Article

\title{
Transposon Insertion in the purL Gene Induces Biofilm Depletion in Escherichia coli ATCC 25922
}

\author{
Virginio Cepas ${ }^{\dagger}{ }^{+}$, Victoria Ballén ${ }^{\dagger}$, Yaiza Gabasa, Miriam Ramírez, Yuly López * and \\ Sara $\mathbf{M}^{\text {a }}$ Soto * \\ ISGlobal, Hospital Clínic_Universitat de Barcelona, 08036 Barcelona, Spain; virginio.cepas@isglobal.org (V.C.); \\ victoria.ballen@isglobal.org (V.B.); yaiza.gabasa@isglobal.org (Y.G.); miriam.ramirez@isglobal.org (M.R.) \\ * Correspondence: yuly.lopez@isglobal.org (Y.L.); sara.soto@isglobal.org (S.M.S.) \\ $\dagger$ These authors contributed equally to this work.
}

Received: 7 August 2020; Accepted: 19 September 2020; Published: 22 September 2020

\begin{abstract}
Current Escherichia coli antibiofilm treatments comprise a combination of antibiotics commonly used against planktonic cells, leading to treatment failure. A better understanding of the genes involved in biofilm formation could facilitate the development of efficient and specific new antibiofilm treatments. A total of $2578 \mathrm{E}$. coli mutants were generated by transposon insertion, of which 536 were analysed in this study. After sequencing, Tn263 mutant, classified as low biofilm-former (LF) compared to the wild-type (wt) strain (ATCC 25922), showed an interruption in the purL gene, involved in the de novo purine biosynthesis pathway. To elucidate the role of purL in biofilm formation, a knockout was generated showing reduced production of curli fibres, leading to an impaired biofilm formation. These conditions were restored by complementation of the strain or addition of exogenous inosine. Proteomic and transcriptional analyses were performed to characterise the differences caused by purL alterations. Thirteen proteins were altered compared to wt. The corresponding genes were analysed by qRT-PCR not only in the Tn263 and wt, but also in clinical strains with different biofilm activity. Overall, this study suggests that purL is essential for biofilm formation in E. coli and can be considered as a potential antibiofilm target.
\end{abstract}

Keywords: biofilm; E. coli; purL; transposon insertion; curli fibers

\section{Introduction}

Escherichia coli is a well-characterised microorganism frequently used as a laboratory model and in industrial microbiology [1]. In the human body, most gut-resident $E$. coli prevent colonisation by pathogenic bacteria and favour the host by producing vitamin $\mathrm{K}$ and B12, which are essential during the blood coagulation process and the formation of red blood cells, respectively [2-4]. However, some E. coli can also cause intestinal or extraintestinal infections such as urinary tract infections (UTIs), meningitis, and neonatal sepsis [5-9]. E. coli grows as free-living cells or biofilm-forming communities. Microbial biofilms are well-organized communities where microorganisms live embedded in a self-produced extracellular polymeric substance (EPS) which protects against adverse environmental conditions [6]. Biofilms are ubiquitous, being found attached to biological or inert surfaces in diverse ecological niches. In addition, E. coli biofilms cause several medical device-related infections, including joint infections, intravascular catheter infections, and catheter-associated urinary tract infections (CAUTI) $[6,10,11]$. Unfortunately, biofilm-forming organisms have an increased tolerance to antibiotics due to the reduced penetration of the antibiotic through the biofilm extracellular matrix (ECM) [12,13]. Likewise, the bacteria within the biofilms evade the immune system through various defence mechanisms, such as by avoiding the complement system and phagocytosis or by acting as a physical barrier [12]. Therefore, there is an unmet need to elucidate new ways to treat biofilm-related infections. In this 
sense, to understand the molecular mechanisms underlying biofilm formation, it is essential to develop efficient new clinical treatments. Several studies have described the mechanisms and gene regulation involved during the three general phases of biofilm formation: attachment, development, and dispersal $[8,14-17]$. For example, some of the well-characterised virulence factor genes among E. coli strains during the initial stages include type 1 fimbriae or pili, curli fimbriae, and flagella. Specifically, disruption in fim genes (fimA and fim H, that encode type-1 fimbrial protein A chain and type 1 fimbrin D-mannose specific adhesion, respectively) reduces initial attachment to abiotic surfaces and biofilm production [18]. Curli fimbriae, encoded by the $\operatorname{csg} B A C$ operon, provide initial adhesion to abiotic surfaces and promote cell aggregation [19]. Thus, alteration of the $\operatorname{csg} A$ gene triggers reduced biofilm formation due to a decreased production of the main curli protein CsgA subunit [20]. In addition, alterations in genes involved in motility ( $f l i, f l h, m o t$, and che alleles) also decrease biofilm formation [5]. On the other hand, the quorum sensing (QS) system plays a critical role in microbial biofilms during development and dispersal stages.

Despite the current knowledge about these genes, the investigation of new essential genes/proteins during biofilm formation could elucidate unknown candidate genes with a higher potential as antibiofilm targets. In the present study we focus on protein expression and the comparison of gene transcription between an E. coli wt strain and the isogenic defective biofilm mutants (Tn) produced by transposon insertion. Taking this into account, the aim of this work was to identify new genes involved in biofilm formation in E. coli using phenotypic and molecular tools.

\section{Materials and Methods}

\subsection{Culture of E. coli and Electrocompetent Cells}

The E. coli ATCC 25922 reference strain, used as the wt strain in this study, was grown for $24 \mathrm{~h}$ at $37^{\circ} \mathrm{C}$ in Luria Bertani (LB) agar (Miller's LB AGAR, Condalab, Madrid, Spain). Electrocompetent cells were made after the overnight culture of a single colony in LB broth (Miller's LB Broth, Condalab) at $37^{\circ} \mathrm{C}$ with shaking at $180 \mathrm{rpm}$. One millilitre of the overnight culture was used to inoculate $100 \mathrm{~mL}$ prewarmed $\left(37^{\circ} \mathrm{C}\right) \mathrm{LB}$ broth and incubated in aerobic conditions at $37^{\circ} \mathrm{C}$ under shaking at $180 \mathrm{rpm}$. When bacteria reached the mid-log phase (optical density (OD) at $600 \mathrm{~nm}=0.6 \pm 0.2$ ), the cells were incubated on ice for $20 \mathrm{~min}$. Bacterial cells were pelleted at $7000 \times \mathrm{g}$ for $10 \mathrm{~min}$, and washed three times: first with $50 \mathrm{~mL}$ of ice-cold water, second with $25 \mathrm{~mL}$ of ice-cold water, and lastly with $2.5 \mathrm{~mL}$ of ice-cold $10 \%$ glycerol. Electrocompetent cells were aliquoted and stored at $-80{ }^{\circ} \mathrm{C}$.

\subsection{Transposon Mutagenesis}

Transposon mutagenesis was carried out according to the manufacturer's recommendations

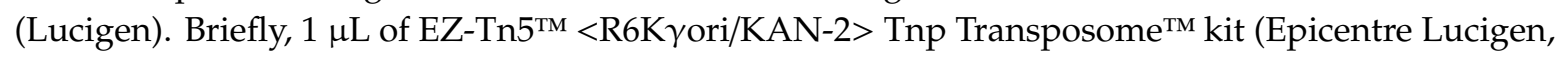
bioNova Científica S.L., Madrid, Spain) was mixed with $45 \mu \mathrm{L}$ of E. coli wt electrocompetent cells and included in a $0.2 \mathrm{~cm}$ electro-cuvette (Bio-Rad, Madrid, Spain). The cells were electroporated using the Pre-Set protocol from the Gene Pulser Xcell ${ }^{\mathrm{TM}}$ Electroporation Systems (Bio-Rad) at $25 \mu \mathrm{F}, 200 \mathrm{Ohms}$, $2500 \mathrm{~V}$. The electroporated cells were recovered immediately in $1 \mathrm{~mL}$ of Super Optimal broth with Catabolite repression (S.O.C.) medium ( $2 \%$ tryptone, $0.5 \%$ yeast extract, $10 \mathrm{mM} \mathrm{NaCl}, 2.5 \mathrm{mM} \mathrm{KCl}$, $10 \mathrm{mM} \mathrm{MgCl}_{2}, 10 \mathrm{mM} \mathrm{MgSO}_{4}$, and $20 \mathrm{mM}$ glucose) and incubated at $37^{\circ} \mathrm{C}$ with shaking (100 rpm) for $60 \mathrm{~min}$. The incubated product was diluted 1:10, and $50 \mu \mathrm{L}$ aliquots were plated onto LB agar with kanamycin-50 $\mu \mathrm{g} / \mathrm{mL}$. Each colony grown was stored separately at $-80^{\circ} \mathrm{C}$ in BD Difco ${ }^{\mathrm{TM}}$ Skim Milk (Becton Dickinson, Madrid, Spain) for further analysis. The efficiency of the electrocompetent cells was $>10^{7}$ colony forming units (CFU)/ $\mu \mathrm{g}$ of DNA.

\subsection{Biofilm Analysis}

Five hundred and thirty-six of a total of 2578 transposon mutants were characterised in terms of biofilm production using a protocol previously standardised in our research group [21]. Briefly, 
all isolates were cultured overnight in LB agar at $37^{\circ} \mathrm{C}$ in aerobic conditions. The cultures were established by the direct colony suspension method at $37^{\circ} \mathrm{C}$ with shaking (180 rpm) in LB broth and then grown overnight. After incubation, colonies were diluted 1:100 in $200 \mu \mathrm{L}$ of M63 medium $\left(13.5 \mathrm{~g} / \mathrm{L} \mathrm{KH}_{2} \mathrm{PO}_{4}, 2 \mathrm{~g} / \mathrm{L}\left(\mathrm{NH}_{4}\right)_{2} \mathrm{SO}_{4}, 5.0 \times 10^{-4} \mathrm{~g} / \mathrm{L} \mathrm{FeSO}{ }_{4}, 1 \mathrm{~mL} 1 \mathrm{M} \mathrm{MgSO}_{4} \cdot 7 \mathrm{H}_{2} \mathrm{O}\right)$, supplemented with $0.25 \%$ glucose and adjusted to $\mathrm{pH} 7$ (with $\mathrm{KOH}$ ) and tested in 96-well flat-bottomed non-treated polystyrene microtiter plates with lids (Nunc ${ }^{\mathrm{TM}}$ Edge 2.0, VWR International, Barcelona, Spain) at $30{ }^{\circ} \mathrm{C}$ for $48 \mathrm{~h}$. After incubation, biofilm was quantified using a crystal violet technique previously described by our group [21]. In brief, liquid culture from M63 medium was carefully removed, and the biofilm mass was washed twice with $210 \mu \mathrm{L}$ of $1 \times$ phosphate-buffered saline (PBS) (pH 7.2) and dried at $65{ }^{\circ} \mathrm{C}$ for at least $20 \mathrm{~min}$. Biofilms were stained with $200 \mu \mathrm{L}$ of $2 \%(v / v)$ solution of crystal violet $(\mathrm{CV})$ and incubated for $10 \mathrm{~min}$ at room temperature. Afterwards, the $\mathrm{CV}$ was completely removed, washed twice with $1 \times \mathrm{PBS}$ and heat-fixed at $65^{\circ} \mathrm{C}$ for $60 \mathrm{~min}$. The $\mathrm{CV}$ was eluted by adding $200 \mu \mathrm{L}$ of $33 \%$ acetic acid. Biofilm formation was measured at $580 \mathrm{~nm}$ using a Microplate Spectrophotometer (EPOCH 2 microplate reader, BioTek, Winooski, VT, USA).

The biofilm production of each sample was tested in triplicate, and samples showing an absorbance less than or equal to the positive control (ATCC 25922) were retested. Finally, the mutants were classified into three groups using the paired Student's $t$-test (adjusted $p<0.05$, considered significant and listed in Supplementary Table S1) comparing the normalised absorbance of each mutant (A Tn) with the absorbance of the reference strain (A ATCC). Only statistically different strains were considered to be LF or high biofilm formers (HF), whereas no statistically significant differences were considered as biofilm formers (F).

\subsection{Phenotypic Characterization of Mutants}

\subsubsection{Growth Curves}

To detect deficiencies in bacterial growth, the fitness of the selected mutants was tested. A single colony of each strain was grown overnight in LB broth at $37^{\circ} \mathrm{C}$ with shaking at $180 \mathrm{rpm}$. After incubation, cultures were centrifuged and adjusted at $\mathrm{OD}_{600 \mathrm{~nm}}=1$ with fresh $\mathrm{LB}$, followed by dilution of 1:100 and plated onto 96-well flat-bottomed polystyrene microtiter plates with lids (Nunc ${ }^{\mathrm{TM}}$ Edge 2.0, VWR International, Barcelona, Spain). The plates were incubated at $37^{\circ} \mathrm{C}$ with double orbital shaking (180 rpm). The absorbance was measured every $15 \mathrm{~min}$ for $24 \mathrm{~h}$ using the Epoch 2 Microplate Spectrophotometer. Each sample was repeated four times. LB without inoculum was used as a negative control. A plot of the natural log (Ln) of Absorbance versus time during the exponential phase yielded a straight line and the slope of this was equal to the specific growth rate $(\mu)$. The $\mu$ obtained for each strain was statistically compared to the $\mu$ of the wt strain.

Bacterial growth in M63 broth was measured by colony counting instead of Epoch 2, as the low growth of the mutant strain and the colourless medium limits its detection by spectrophotometer. Bacterial viability was also measured using the LIVE/DEAD ${ }^{\circledR}$ BacLight Bacterial Viability Kit, which uses mixtures of $S Y T O^{\circledR} 9$ green-fluorescent nucleic acid stain and the red-fluorescent nucleic acid stain, propidium iodide (PI). According to the manufacturer, when both dyes are present, it is possible to distinguish between intact and damaged bacterial cells. PI penetrates only into bacteria with damaged membranes, causing a reduction in the SYTO ${ }^{\circledR} 9$ stain. Thus, bacteria with intact cell membranes stain fluorescent green, whereas bacteria with damaged membranes stain fluorescent red. Therefore, after incubation, biofilms were washed twice with $1 \times \mathrm{PBS}$ ( $\mathrm{pH}$ 7.2), cells were detached with a scraper, transferred into an Eppendorf tube, and sonicated at $37 \mathrm{kHz}$ for 2 min using an ultrasonic bath (Fisher Scientific FB 15053, Waltham, MA, USA) following by vigorous vortexing for $1 \mathrm{~min}$. The cells were then stained following the kit protocol and observed in the Olympus IX51 inverted fluorescence microscope. Three biological and technical replicates were done and three fields of each well were observed and imaged using the Fiji ImageJ software. Integrated density (staining intensity), defined as the sum of the values of the pixels in the image selected was measured and the percentage of viability was calculated. 


\subsubsection{Swimming Assay}

A motility assay was performed as previously described [9]. Briefly, transposon mutant bacteria were incubated onto LB-kanamycin plates for $24 \mathrm{~h}$ at $37^{\circ} \mathrm{C}$. After incubation, a single colony was streaked in a $0.3 \%$ LB agar tube with $0.001 \%$ 2,3,5-triphenyl tetrazolium chloride (TTC). The tubes were incubated for $20 \mathrm{~h}$ at $37^{\circ} \mathrm{C}$. All completely red-stained tubes were considered positive. A motility assay was performed in triplicate for each strain.

\subsubsection{Congo Red Assay}

Curli production was determined using the Congo Red (CR) assay as previously described by Prigent-Combaret et al. [20]. YESCA-CR agar plates were made with yeast extract and casamino acid agar (YESCA: $1 \mathrm{~g} \mathrm{~L}^{-1}$ yeast extract, $10 \mathrm{~g} \mathrm{~L}^{-1}$ casamino acids, $20 \mathrm{~g} \mathrm{~L}^{-1}$ agar), and autoclaved at $121^{\circ} \mathrm{C}$. After sterilisation, filter-sterilised CR and Brilliant Blue $\mathrm{G}\left(100 \mu \mathrm{g} \mathrm{mL} \mathrm{L}^{-1}\right.$ and $10 \mu \mathrm{g} \mathrm{mL}{ }^{-1}$ final concentrations, respectively) were added. Transposon mutants were streaked in LB broth and grown at $37^{\circ} \mathrm{C}$ overnight. Five microliters of overnight culture were spotted on the centre of the $\mathrm{CR}$ agar plate and incubated at $28^{\circ} \mathrm{C}$ for $48 \mathrm{~h}$. Dark red colonies were indicative of adhesion fibers while white or light pink colonies were indicative that fibers were not produced.

\subsubsection{Hemagglutination Assays}

Type 1 fimbriae (pili) can be tested by hemagglutination assays. The fim $H$ gene encoded the mannose-specific adhesin, located at the end of the pilus, resulting in hemagglutination in the presence of mannose. Therefore, the presence of hemagglutination in the samples indicated the expression of FimH adhesin. The assay was performed according to the protocol described by Hultgren et al. [22]. Bacterial cells were grown overnight in LB agar. After incubation, each strain was suspended in $1 \times$ PBS to obtain an $\mathrm{OD}_{600 \mathrm{~nm}}$ of 1.0. One $\mathrm{mL}$ of the suspension was centrifuged, and the pellet was resuspended in $0.1 \mathrm{~mL}$ of $1 \times$ PBS. Twenty-five $\mu \mathrm{L}\left(1 \times 10^{9}\right.$ to $2 \times 10^{9}$ bacteria) were serially diluted in 96-well round-bottomed polystyrene microtiter plates containing $25 \mu \mathrm{L}$ of $1 \times$ PBS in each well. An equal volume of $2.5 \%$ previously washed sheep erythrocytes was added and, after mixing, the plates were incubated at $4{ }^{\circ} \mathrm{C}$ for 4 to $18 \mathrm{~h}$. The endpoint was defined as the highest dilution at which erythrocyte buttons were not observed. The titre was expressed as the reciprocal of the endpoint and then expressed in $\log _{2}$.

\subsection{Genotypic Characterization of Mutants}

\subsubsection{DNA Sequencing}

Two mutants with the most significant loss of ability to form biofilm were selected for DNA sequencing. Each strain was cultured onto LB agar plates at $37^{\circ} \mathrm{C}$ in aerobic conditions for $24 \mathrm{~h}$. One colony was inoculated in $5 \mathrm{~mL}$ of LB broth and placed on ice when the OD reached mid-log phase. DNA extraction was performed using the Bacterial Genomic DNA Isolation Kit (Norgen Biotek Corp, Schmon Pkwy, Thorold, ON, Canada) following the manufacturer's recommendations. Then, DNA was quantified using a Qubit 4 Fluorometer (Thermo Scientific, Waltham, MA, USA).

The genomic DNA material was used for the preparation of TrueSeq Illumina libraries (Illumina Inc, San Diego, CA, USA). The Illumina HiSeq2500 system was used as a sequencing platform with a $2 \times 125$ bp paired-end strategy to generate 6,000,000 reads. The libraries were checked for quality analysis using FASTQC available at (http://www.bioinformatics.bbsrc.ac.uk/projects/fastqc/) implemented by the GPRO suit (https://gpro.biotechvana.com/).

The FASTQ files were pre-processed using Cutadapt software to remove primer adapters [23] and the sequencing quality was established with Prinseq with which reads with less than $50 \mathrm{bp}$ and a concentration of up to $15 \%$ of Ns were discarded [24]. Then, de novo genome assemblies were conducted with the SPAdes Genome Assembler [25]. Reads were mapped onto the reference 
genome (Escherichia coli: GenBank: CP009072.1) using Bwa software [26]. The transposon was detected comparing the reconstructed genome to wt strain using the Mauve software [27].

\subsection{2. purL Gene Disruption}

To confirm the role of purL in biofilm formation, the disruption of this gene was done using the $\lambda$ red recombination system according to the protocol described by Datsenko and Wanner [28]. Briefly, the E. coli wt electrocompetent cells were electroporated with $50 \mathrm{ng}$ of a red recombinase expression plasmid (pKD46). Transformants were grown in LB broth with ampicillin $100 \mu \mathrm{g} / \mathrm{mL}$ (Sigma-Aldrich, Milwaukee, WI, USA), and L-arabinose $10 \mathrm{mM}$ (TCI Europe, Zwijndrecht, Belgium), at $30{ }^{\circ} \mathrm{C}$ to an $\mathrm{OD}_{600}$ of $0.6 \pm 0.2$ and then were remade as electrocompetent cells.

The deletion of purL was obtained by PCR. To generate the PCR fragments, the primers were designed by priming, upstream and downstream, the sites flanking the chloramphenicol resistance gene in pKD3 and with ends homologous to upstream and downstream chromosomal sequences for targeting the purL gene. N-terminal deletion primer had a 50-nt 5'extension including the gene initiation codon and the 21-nt sequence 5'-GTGTAGGCTGGAGCTGCTTCG-3'. C-terminal deletion primers consisted of $21 \mathrm{nt}$ for the C-terminal region including the termination codon, 29-nt downstream, and the 20-nt sequence 5'-CATATGAATATCCTCCTTAG-3'. The designed primers were: 5'-CGTTTCCCCCCCTTGGGTACACCGAAAGCTTAGAAGACGAGAGACTTATGGTGTA GGCTGGAGCTGCTTCG-3' and 5'-CCGGGCTGCAATACCAATGGGTTGACGACTTACCCCAAC TGCTTACGTGCCATATGAATATCCTCCTTAG-3' (Metabion).

PCR products were gel-purified with the E.Z.N.A. ${ }^{\circledR}$ Gel Extraction Kit (Omega Bio-tek, Norcross, GA, USA) and digested with DpnI (Thermo Scientific ${ }^{\mathrm{TM}}$, Waltham, MA, USA). $500 \mathrm{ng}$ of the re-purified product were mixed with $100 \mu \mathrm{L}$ of electrocompetent cells carrying the pKD46 and electroporated. The cells were immediately added to $1 \mathrm{~mL}$ S.O.C. medium, incubated at $37^{\circ} \mathrm{C}$ with shaking $(180 \mathrm{rpm})$ for $2 \mathrm{~h}$, centrifuged, and resuspended in $500 \mu \mathrm{L}$ of fresh S.O.C. medium. Then, $250 \mu \mathrm{L}$ were spread onto each LB agar plate containing chloramphenicol $(\mathrm{Cm}) 10 \mu \mathrm{g} / \mathrm{mL}$ to select $\mathrm{Cm}$-resistant transformants. Afterwards, the obtained transformants were incubated at $43^{\circ} \mathrm{C}$ in LB agar without antibiotics and tested for ampicillin sensitivity to test for loss of the pKD46 helper plasmid. Each colony was stored separately at $-80^{\circ} \mathrm{C}$ in BD Difco ${ }^{\mathrm{TM}}$ Skim Milk (Becton Dickinson, Madrid, Spain) for further analysis. Different PCRs were performed to demonstrate the successful disruption of the purL gene. The primers used are listed in Supplementary Table S2.

The growth curve, biofilm formation, and curli fibers formation of the $\Delta p u r L:: c a t$ knockout were also evaluated as previously described.

\subsection{3. purL Gene Complementation}

The knockout strain was complemented to recover biofilm formation capacity. Briefly, purified PCR product of the purL gene was ligated to $\mathrm{PGEM}^{\circledR}$-T vector System (Promega, Madison, WI, USA) using the T4 DNA Ligase and cloned into the competent knockout strain. The complemented bacteria were selected in LB agar plates containing ampicillin $100 \mu \mathrm{g} / \mathrm{mL}$. Each colony was stored separately at $-80{ }^{\circ} \mathrm{C}$ in Skim Milk for further analysis. Successful complementation was confirmed by PCR using the T7 promoter primer and an internal primer of the purL gene (Supplementary Table S2). Then, the biofilm formation, growth curves, and curli production tests of the complemented bacteria were assessed.

\subsubsection{Effect of Inosine Addition to the Biofilm Formation Ability of the purL Mutant.}

To examine the recovery of the ability to form biofilm of the purL mutant by the addition of an exogenous source of purine, M63 broth supplemented with double decreasing concentrations of inosine ranging between 50 and $1.56 \mu \mathrm{g} / \mathrm{mL}$ was used for biofilm formation analysis and growth curves, following the protocols previously described. Curli production was also measured by supplementing YESCA-CR agar with inosine $50 \mu \mathrm{g} / \mathrm{mL}$. 


\subsection{Proteomic Characterization of Mutants}

\subsubsection{Protein Isolation}

The protein isolation of the wt strain, as well as the proteomic isolation of the Tn263, the E. coli mutant selected for proteomic and transcriptional analysis, was performed as follows: the strains were cultured inoculating a single colony into LB broth for $18 \mathrm{~h}$ at $37^{\circ} \mathrm{C}$ with shaking at $180 \mathrm{rpm}$ to reach a cell concentration of $1 \times 10^{9} \mathrm{CFU} / \mathrm{mL}$. Colonies were diluted 1:100 in $70 \mathrm{~mL}$ of M63 medium supplemented with $0.25 \%$ glucose in a T75 non-treated flask (Thermo Scientific ${ }^{\mathrm{TM}}$ Nunc $^{\mathrm{TM}}$, Waltham, MA, USA) and incubated at $30^{\circ} \mathrm{C}$ for $72 \mathrm{~h}$ without shaking. The medium was carefully replaced by a fresh medium every $24 \mathrm{~h}$. Subsequently, the medium was aspirated to remove planktonic cells, and flasks were washed twice with $20 \mathrm{~mL}$ of $1 \times \mathrm{PBS}$ (pH 7.2) to remove unattached or loosely attached cells. Cells were then resuspended with $25 \mathrm{~mL}$ of $10 \mathrm{mM}$ Tris- $\mathrm{KCl}(\mathrm{pH} 7.8,150 \mathrm{mM} \mathrm{KCl})$ and sonicated at $37 \mathrm{kHz}$ for 4 min using an ultrasonic bath (Fisher Scientific FB 15053, Waltham, MA, USA). Cells were harvested in $50 \mathrm{~mL}$ sterile falcon tubes (Deltalab, Rubí, Spain) and spun down at $3500 \times g$ for $10 \mathrm{~min}$ at $4{ }^{\circ} \mathrm{C}$. The cell pellet was washed 3 times in $50 \mathrm{~mL}$ of Tris- $\mathrm{KCl}$ and finally transferred into an Eppendorf tube and pelleted at $12,000 \times \mathrm{g}$ for $10 \mathrm{~min}$ at $4{ }^{\circ} \mathrm{C}$. The pellet was homogenized in lysis buffer (7M urea, 2M thiourea, 4\% CHAPS, 2\% ASB-14), and supplemented with protease inhibitor (GE Healthcare, Chicago, IL, USA). Bacterial cells were broken by sonication for 10 min with a cycle of $20 \mathrm{~s}$ on $/ 59 \mathrm{~s}$ off at $4{ }^{\circ} \mathrm{C}$ on ice-water. After cell disruption, the samples were centrifuged at $3500 \times g$ for $15 \mathrm{~min}$ at $4{ }^{\circ} \mathrm{C}$, and the supernatant was aliquoted and stored at $-80^{\circ} \mathrm{C}$. The protein extracts were quantified using the 2-D Quant Kit and purified with the 2-D Clean-Up Kit (GE Healthcare). Fifty $\mu \mathrm{g}$ of protein was added to $0.5 \%$ of immobilized $\mathrm{pH}$ gradient buffer $4-7$ and $20 \mathrm{mM}$ of dithiothreitol (DTT). Each sample was assessed in three biological replicates.

\subsubsection{Two-Dimensional SDS-PAGE Analysis}

Two-dimensional sodium dodecyl sulfate polyacrylamide gel (2D SDS-PAGE) was performed as previously described [29]. Briefly, the Immobiline DryStrip Gels (IPG strips) (GE Healthcare) were hydrated following the manufacturer's recommendations for $18 \mathrm{~h}$ at room temperature. The protein sample was loaded onto an IPG strip for first dimension separation by isoelectric focusing using $24 \mathrm{~cm} \mathrm{pH} \mathrm{4-7} \mathrm{linear} \mathrm{IPG} \mathrm{strips} \mathrm{for} 20 \mathrm{~h}(200 \mathrm{~V}$ for $2 \mathrm{~h}, 500 \mathrm{~V}$ for $3 \mathrm{~h}, 1000 \mathrm{~V}$ for $4 \mathrm{~h}$, and $8000 \mathrm{~V}$ for $11 \mathrm{~h}, 20^{\circ} \mathrm{C}$ ) in an IPGphor I (GE Healthcare). After focusing, each strip was equilibrated in $10 \mathrm{~mL}$ of equilibration buffer (6M Urea, $75 \mathrm{mM}$ Tris-HCl pH 8.8, 29.3\% glycerol, $2 \%$ SDS and $0.002 \%$ bromophenol blue supplemented with DTT or iodoacetamide and 1\% DTT) for $15 \mathrm{~min}$ and acetylated with iodoacetamide, and subsequently placed onto $12.5 \%$ polyacrylamide gels $(24 \mathrm{~cm} \times 20 \mathrm{~cm})$ prepared as described by Laemmli [30]. The second dimension was performed using an Ettan ${ }^{\mathrm{TM}}$ DALT six system (GE Healthcare). Gels were run at $20^{\circ} \mathrm{C}$ using $80 \mathrm{~V}, 10 \mathrm{~mA} /$ strip, and $1 \mathrm{~W} /$ strip for $1 \mathrm{~h}$, followed by $500 \mathrm{~V}, 40 \mathrm{~mA} / \mathrm{strip}$ and $13 \mathrm{~W} /$ strip until the bromophenol blue tracking front had run off the end of the gel.

\subsubsection{Gel Staining and Protein Detection}

Two-dimensional gels were silver stained as described previously [31]. Briefly, the gels were fixed for $18 \mathrm{~h}$ in $40 \%$ ethanol and 10\% acetic acid, followed by incubation in sensitizing solution for $1 \mathrm{~h}$ in $30 \%$ ethanol with $0.02 \%(w / v)$ sodium thiosulfate. The gels were washed three times in distilled water for $5 \mathrm{~min}$ and treated with $0.1 \%(w / v)$ silver nitrate for $30 \mathrm{~min}$. The gels were washed again twice with distilled water for $1 \mathrm{~min}$. The developing step was performed with $3 \%(w / v)$ sodium carbonate and $0.025 \%(v / v)$ formaldehyde until the desired contrast was reached. Developing reaction was stopped with $1.5 \%(w / v)$ EDTA (Ethylenediaminetetraacetic acid)- $\mathrm{Na}_{2}$ for $45 \mathrm{~min}$. Finally, the gels were washed twice with distilled water. 


\subsubsection{Mass-Spectrometry Analysis for Orbitrap}

Selected protein spots were excised from the gels digested with trypsin and analysed by liquid chromatography coupled to mass spectrometry (Orbitrap Velos, Thermo, Waltham, MA, USA), as described previously [32]. Proteins were identified through searching against $E$. coli proteins found in the UniProt database, using Mascot (Matrix Science, London, UK) to search the SwissProt database (2018_11, taxonomy restricted to E. coli proteins). Tandem mass spectrometry (MS/MS) spectra were sought with a precursor mass tolerance of $10 \mathrm{ppm}$, fragment tolerance of $0.05 \mathrm{Da}$, trypsin specificity with a maximum of two missed cleavages, cysteine carb-amido-methylation set as fixed modification, and methionine oxidation as variable modification. The significance threshold for the identifications was set at $p<0.05$, with a minimum ions score of 20 .

\subsubsection{RNA Isolation and cDNA Synthesis}

E. coli ATCC 25922, the transposon mutant strain Tn263, as well as three biofilm-forming and three non-biofilm-forming clinical isolates were used for further gene expression analyses. Clinical strains belonging to a collection of our research group were collected over six months between 2016 and 2017 from different hospitals in Barcelona, Spain). All strains had been previously identified by MALDI-TOF mass spectrometry and their antimicrobial profile was tested according to the M100 guidelines (Clinical \& Laboratory Standards Institute, CLSI 2019) [33]. Origins of isolation and antibiotic resistance profiles are shown in Supplementary Table S3. The strains were cultured by inoculating a single colony into LB broth for $18 \mathrm{~h}$ at $37^{\circ} \mathrm{C}$ with shaking at $180 \mathrm{rpm}$ to reach a cell concentration of $1 \times 10^{9} \mathrm{CFU} / \mathrm{mL}$. Colonies were diluted 1:100 in $70 \mathrm{~mL}$ of $\mathrm{M} 63$ medium supplemented with $0.25 \%$ glucose in a T75 flask for $72 \mathrm{~h}$ and $30^{\circ} \mathrm{C}$ without shaking. Subsequently, the medium was aspirated to remove planktonic cells, and flasks were washed twice with $20 \mathrm{~mL}$ of sterilized $1 \times \mathrm{PBS}$ (pH 7.2). Cells were resuspended in $3 \mathrm{~mL}$ of $1 \times$ PBS and treated with $6 \mathrm{~mL}$ of RNAprotect Bacteria Reagent (Qiagen, Hilden, Germany) and vortexed and centrifuged at $5000 \mathrm{rpm}$ for $20 \mathrm{~min}$ at room temperature. The supernatants were discarded, and the pellets were treated with TE-lysozyme buffer $(3 \mathrm{mg} / \mathrm{mL}$ in TE buffer $\mathrm{pH}$ 7.4). Afterwards, RNA was extracted using the RNeasy Mini Kit (Qiagen) according to the manufacturer's recommendations. The total RNA was eluted in $50 \mu \mathrm{L}$ of RNase-free water. RNA was isolated from four independent samples.

The extracted RNA was treated with DNA-free ${ }^{\mathrm{TM}}$ Kit DNase Treatment and Removal Reagents (Ambion, by Life Technologies AM1906, Waltham, MA, USA) to remove DNA contamination. After DNase treatment, RNA was tested for residual genomic DNA contamination by polymerase chain reaction (PCR) amplification of the adk gene and gel electrophoresis.

The total RNA concentration was quantified using NanoDrop 1000 (Thermo Scientific, Waltham, MA, USA). An A260/280 ratio between 1.80 and 2.10 was considered optimal for RNA quality. cDNA was synthesized using $500 \mathrm{ng}$ of RNA in a reaction volume of $20 \mu \mathrm{L}$ and the qScript cDNA SuperMix reagent (Quanta Bioscience, 95048-100, Gaithersburg, MD, USA). The PCR amplification protocol consists of one incubation step at $25^{\circ} \mathrm{C}$ for $5 \mathrm{~min}$, a DNA polymerization step at $42{ }^{\circ} \mathrm{C}$ for $30 \mathrm{~min}$, and a final enzyme deactivation step at $85^{\circ} \mathrm{C}$ for $5 \mathrm{~min}$. The final PCR product was diluted 1:10 and stored at $-20^{\circ} \mathrm{C}$. cDNA was used as a template for quantitative reverse transcription PCR (qRT-PCR) assays.

\subsubsection{Gene Expression by qRT-PCR}

qRT-PCR was carried out using $10 \mu \mathrm{L}$ of PowerUp ${ }^{\text {TM }}$ SYBR Green Master Mix (Applied Biosystems, Thermo Fisher Scientific, A25742, Foster City, CA, USA), $1 \mu \mathrm{L}$ of primer mix (each reverse and forward primers at a final concentration of $0.5 \mu \mathrm{M}), 4 \mu \mathrm{L}$ of RNase-free water and $5 \mu \mathrm{L}$ of cDNA template.

Reactions were conducted in duplicate and the $\operatorname{arc} A$ gene was used as the reference gene for normalisation of CT-values [34,35]. A non-template control reaction mixture was included for each gene. Amplification was performed using StepOnePlus ${ }^{\mathrm{TM}}$ Real-Time PCR Systems (Applied Biosystems, Foster City, CA, USA) being the cycling conditions: a pre-incubation step of $95^{\circ} \mathrm{C}$ at $15 \mathrm{~min}$, followed 
by an amplification step of $95^{\circ} \mathrm{C}$ for $10 \mathrm{~s}, 60^{\circ} \mathrm{C}$ for $30 \mathrm{~s}$ and $72{ }^{\circ} \mathrm{C}$ for $30 \mathrm{~s}$ repeated for 44 cycles, and a melting curve analysis from $60{ }^{\circ} \mathrm{C}$ to $95{ }^{\circ} \mathrm{C}$ in $0.3^{\circ} \mathrm{C}$ intervals. The relative fold-change of mRNA transcripts in biofilms compared to mutant cultures was calculated using the $2^{-\Delta \Delta C t}$ method. The primers used are listed in Supplementary Table S4. The primers designed in this study were made using Primer Express Software v.3.0.1 (Applied Biosystems). Data analysis was based on at least three independent experiments.

\subsection{Data Plotting and Statistical Analysis}

All statistical analyses were performed using GraphPad Prism v8.0.2 software (La Jolla, CA, USA) unless otherwise stated. Graphs were created using GraphPad Prism v8.0.2 software and Tableau Software (Seattle, WA, USA). Growth rates were evaluated via two-tailed Student $t$-test. One-way ANOVA followed by post hoc Dunnett's multiple comparison tests were used to analyse colony counting in M63, LIVE/DEAD assay, and biofilm quantification after the addition of inosine. Statistical quantification of relative protein levels was analysed with Progenesis SameSpots 4.6.206 (Totallab, Newcastle, UK) and evaluated via ANOVA. The relative transcript levels of selected genes in wt strain, Tn263 mutant and clinical isolates were calculated using the $2^{-\Delta \Delta C t}$ method. Two-tailed student $t$-test was performed to compare wt vs Tn263 and biofilm-former vs non-biofilm former Differences were considered statistically significant with a $p$ value $<0.05$.

\section{Results}

\subsection{Mutant Selection by Biofilm Assays}

A total of 2578 E. coli mutants by transposon insertion were generated, of which 536 were analysed in this study. The mutants were further studied for their ability to form biofilm and compared to the wt strain. Mutants presenting reduced biofilm-formation capacity (Table S1) were selected. A total of 116 mutants showed an altered biofilm formation rate in comparison with the wt strain. Among these, 20 were classified into the low biofilm formers (LF) group (3.73\%) with an absorbance between 0.065 and $0.584,420$ mutants classified as formers (F) $(78.36 \%)$ with an absorbance from 0.588 to 1.414 and finally 96 were classified into the high biofilm formers (HF) $(17.91 \%)$ with an absorbance higher than 1.414 (Figure 1). Into the low biofilm formers, Tn263 and Tn463 mutants showed the most significant loss of biofilm formation with values of absorbance of 0.065 and 0.159 , respectively.

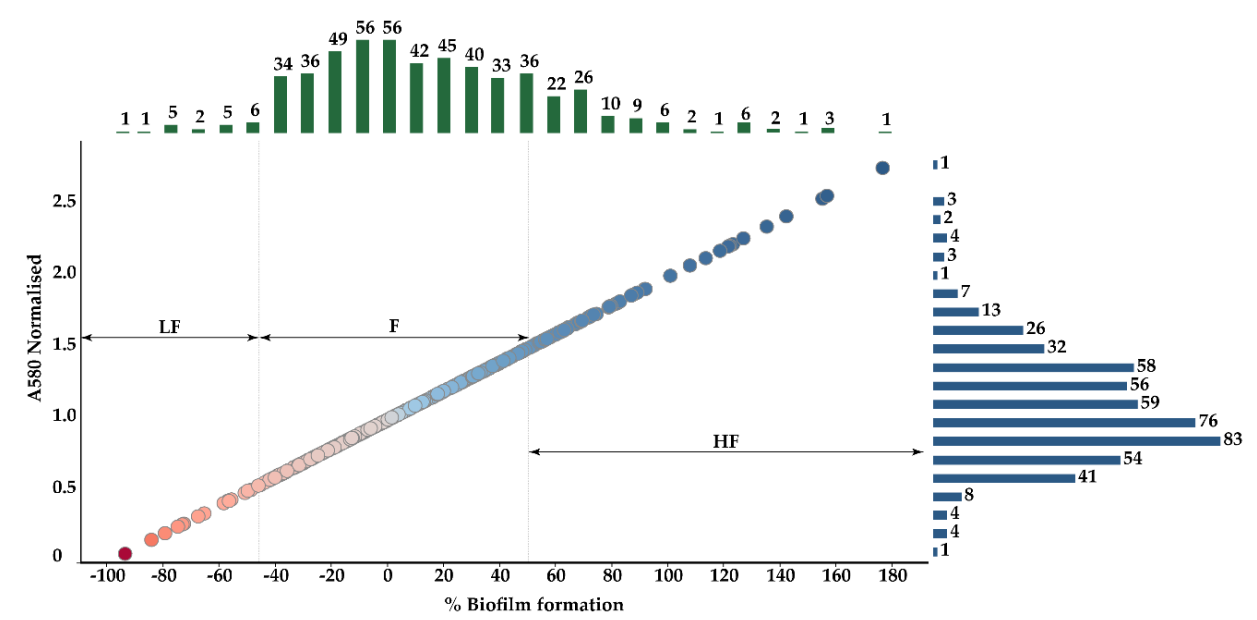

Figure 1. Scatter plot and marginal histograms of the mutants. Upper bars (green) indicate the number of strains in the respective percentage of biofilm formation. Right bars (blue) indicate the number of stains in the respective absorbance values. Each spot represents a mutant where red colour indicates low biofilm formation rates and blue corresponds to high biofilm formation rates. LF: low biofilm former; F: biofilm former; HF: high biofilm former; A: absorbance. 


\subsection{Phenotypic Characterization of Mutants}

The 20 mutants classified into the low biofilm-forming capacity group (LF) were assessed with a phenotypic comparative study.

\subsubsection{Growth Curves in LB Broth}

Transposon insertion can affect essential metabolic pathways and alter normal physiological development. To detect these possible defects, growth curves were evaluated on $20 \mathrm{LF}$ mutant strains and compared to the wt strain (Figure 2). The analysis of the specific growth rate $(\mu)$ performed in LB broth showed statistically significant differences in the Tn463 mutant in comparison to the wt $(p<0.0001)$. The specific growth rates $(\mu)$ of the other mutant strains were similar to the $\mathrm{wt}$, and no statistically significant differences were found $(p>0.05)$. Figure 2 shows the entire growth curve measuring absorbance every $15 \mathrm{~min}$ until $24 \mathrm{~h}$ of incubation.

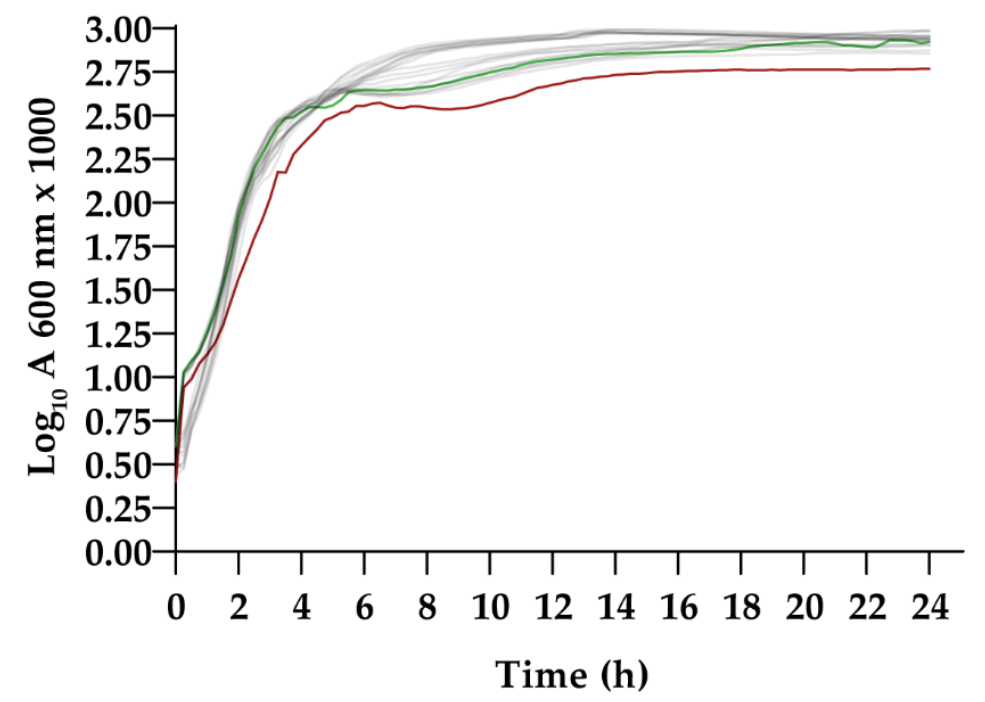

Figure 2. Fitness assay in Luria Bertani (LB) broth. Green represents the wild type curve; Red represents Tn463. Grey represents the other 19 low biofilm-former (LF) transposon mutants, including Tn263. Growth rates were statistically evaluated via two-tailed Student $t$-test.

\subsubsection{Swimming, Congo Red and Hemagglutination Assays}

In this section, 20 mutants were examined according to the phenotypic characterization of nonbiofilm-forming mutants. The results of the swimming, curli fibers production and hemagglutination assays are summarized in Table 1.

In the swimming assay, no samples were found to be non-motile, indicating that defects in biofilm formation are not related to defective flagella. Supplementary Figure S1 shows an example of swimming classification using a defective mutant in the $f h D$ gene as non-motile control and wt as motile control. The ability to form curli fimbriae was evaluated using the CR assay in YESCA-CR plates. In this assay, the Tn463 and Tn263 mutants showed significant differences caused by altered or defective synthesis of curli. The results obtained in this assay are further discussed in Section 3.3.2. Finally, all selected mutants showed positive hemagglutination, suggesting that type 1 pili are not involved in the lack of biofilm formation in these mutants. Since Tn463 and Tn263 showed the the most significant loss of biofilm formation and some changes in these assays, we analysed only these mutants in the next section. 
Table 1. Phenotypical results of selected mutants.

\begin{tabular}{|c|c|c|c|}
\hline Sample & Swimming & Curli Production & Hemagglutination $\left(\log _{2}\right)$ \\
\hline Tn5 & + & + & 10 \\
\hline $\operatorname{Tn} 29$ & + & + & 10 \\
\hline $\operatorname{Tn} 42$ & + & + & 10 \\
\hline $\operatorname{Tn} 82$ & + & + & 10 \\
\hline $\operatorname{Tn} 90$ & + & + & 10 \\
\hline Tn119 & + & + & 10 \\
\hline Tn143 & + & + & 10 \\
\hline Tn 249 & + & + & 10 \\
\hline $\operatorname{Tn} 251$ & + & + & 10 \\
\hline Tn 262 & + & + & 10 \\
\hline $\operatorname{Tn} 263$ & + & - & 10 \\
\hline Tn 337 & + & + & 10 \\
\hline $\operatorname{Tn} 373$ & + & + & 10 \\
\hline Tn 406 & + & + & 10 \\
\hline Tn 420 & + & + & 10 \\
\hline $\operatorname{Tn} 425$ & + & + & 10 \\
\hline $\operatorname{Tn} 457$ & + & + & 10 \\
\hline Tn 463 & + & - & 10 \\
\hline Tn 467 & + & + & 10 \\
\hline Tn 474 & + & + & 10 \\
\hline
\end{tabular}

\subsection{Genotypic Characterization of Mutants}

\subsubsection{DNA Sequencing}

Since this study focused on low-forming strains after transposon insertion, the Tn263 and Tn463 mutants were selected for DNA sequencing. Although this was not within the scope of the present study, the characterisation of the mutants with increased biofilm production could also lead to interesting results and warrants further investigations.

According to the analysis of transposon insertion realised in collaboration with BIOTECHVANA (Valencia, Spain), in the Tn463 mutant, the transposon was inserted in the $\operatorname{csg} A$ and $c y s B$ genes. The $\operatorname{csg} B A C$ operon encodes the curli major subunit protein CsgA, the curli nucleator protein CsgB, and the periplasmic chaperone $\mathrm{CsgC} \mathrm{[36].} \mathrm{The} \mathrm{importance} \mathrm{of} \mathrm{curli} \mathrm{fibers} \mathrm{in} \mathrm{biofilm} \mathrm{formation} \mathrm{has}$ previously been demonstrated as being linked to the synthesis of the exopolysaccharide cellulose, a complementary factor of the biofilm matrix [37]. cysB gene encodes for CysB protein which is a positive regulator of gene expression for the cysteine regulon, a system of ten or more loci involved in the biosynthesis of L-cysteine from inorganic sulfate. Since $\operatorname{csg} A$ is a gene that has been previously related to biofilm formation, we focused only on Tn263 for further analysis. In Tn263, the transposon was only inserted in the purL gene. purL encodes for phosphoribosyl-formyl-glycinamidine synthase, involved in the de novo purine biosynthesis pathway using 5-phospho- $\alpha$-d-ribose 1-diphosphate (PRPP) as a precursor for producing inosine monophosphate (IMP), which is the precursor of adenosine monophosphate (AMP) and guanine monophosphate (GMP) (Figure 3). Interestingly, in our mutant, the transposon insertion is located after $134 \mathrm{bp}$, position 45 in the protein affecting the $\mathrm{N}$-terminal domain and producing an unstable and non-functional protein but not affecting the gene expression. Therefore, purine synthesis appears as an essential function whereby bacteria produce nucleotides for the synthesis of DNA and RNA. Given the impact on the purine biosynthesis pathway, other metabolism alterations in Tn263 were investigated using 2D SDS-PAGE analysis and subsequent protein identification with orbitrap. 


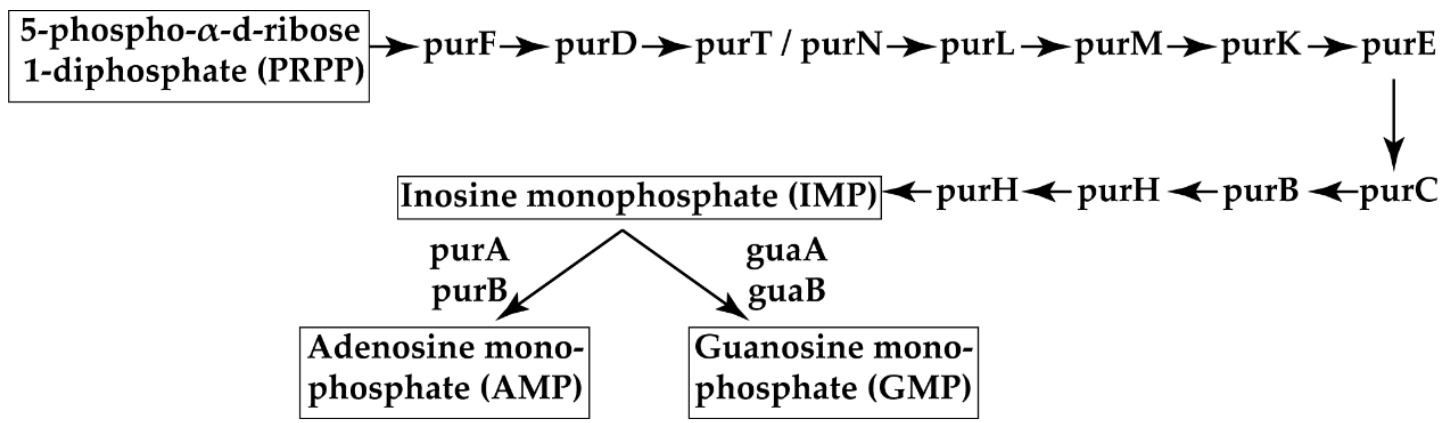

Figure 3. De novo purine biosynthesis in E. coli. Adapted from Kyoto Encyclopedia of Genes and Genomes (KEGG) pathway maps.

\subsubsection{Confirmation of the Role of the purL Gene in Biofilm Formation Using Its Knockout Strain}

The $\Delta$ purL::cat $\left(\mathrm{Cm}^{\mathrm{R}}\right)$, Tn263, and wt strains were cultivated in M63 broth. The mean value of colony-forming units showed statistically significant differences in biofilm as well as planktonic culture in both $\Delta$ purL::cat and the Tn263 mutant strains compared to the wt strain after $72 \mathrm{~h}$ of incubation in M63 broth. In the same line, the measure of integrated density showed significant differences in the total number of cells in biofilm ( $p=0.0002$ and $p=0.0008$, Tn263 and purL mutant, respectively). Nonetheless, the percentages of live and dead bacteria were highly similar between them (Table 2).

Table 2. Colony-forming units and Live/Dead BacLight Bacterial Viability assay.

\begin{tabular}{cccccc}
\hline & \multicolumn{3}{c}{$\log _{\mathbf{1 0}} \mathbf{C F U} / \mathbf{m L} \pm \mathbf{S D}$} & Live/Dead & \\
\cline { 2 - 5 } & Biofilm & Planktonic & Integrated Density & Live (\% \pm SD) & Dead (\% \pm SD) \\
\hline wild type & $9.09 \pm 0.24$ & $8.99 \pm 0.05$ & $2.03 \times 10^{7} \pm 4.86 \times 10^{6}$ & $85.40 \pm 6.30$ & $14.60 \pm 6.30$ \\
Tn263 & $6.40 \pm 0.51$ & $6.96 \pm 0.01$ & $9.69 \times 10^{6} \pm 2.79 \times 10^{6}$ & $86.32 \pm 4.01$ & $13.68 \pm 4.01$ \\
spurL::cat & $6.22 \pm 0.44$ & $7.02 \pm 0.02$ & $1.11 \times 10^{7} \pm 2.34 \times 10^{6}$ & $80.38 \pm 6.88$ & $19.62 \pm 6.88$ \\
\hline
\end{tabular}

However, similar growth curves of the $\Delta p u r L:: c a t$ and the Tn263 mutant strains compared to the wt strain were observed when the M63 culture media was supplemented with inosine $(50 \mu \mathrm{g} / \mathrm{mL})$. The complemented strain $\Delta$ purL/purL+ showed similar growth curves to the wt strain in LB as well as in M63. Supplementation with inosine did not have a significant effect on the growth curve of the complemented strain. It should be noted that the general growth in the supplemented M63 broth shows differences in the Log phase compared to the Log phase obtained with LB broth (Figure 4).

As already observed with the Tn263, the $\Delta$ purL::cat mutant was not able to form biofilm in M63 broth. However, when the medium was supplemented with inosine $(50 \mu \mathrm{g} / \mathrm{mL})$, both the $\Delta p u r L:: c a t$ and the Tn263 mutants recovered the ability to form biofilm. Likewise, no statistically significant differences after One-way ANOVAs followed by post hoc Dunnett's multiple comparisons tests were found using inosine concentrations ranging between 25 and $50 \mu \mathrm{g} / \mathrm{mL}$ for the $\Delta p u r L:: c a t$ and the Tn263 mutants compared to the wt $(p>0.05)$. Nevertheless, inosine concentrations below $25 \mu \mathrm{g} / \mathrm{mL}$ were insufficient to recover the ability to form a biofilm by the purL affected strains (Figure 5). Then, after complementation with the purL gene using the $\mathrm{pGEM}^{\circledR}$-T vector, the knockout strain also recovered the ability to form biofilm, and the addition of inosine did not have a significant effect on its biofilm formation. The complemented strain $\Delta$ purL/purL+ shows similar absorbance values than the wt strain. The addition of inosine does not have a significant effect on its ability to form biofilm. 
(a) LB

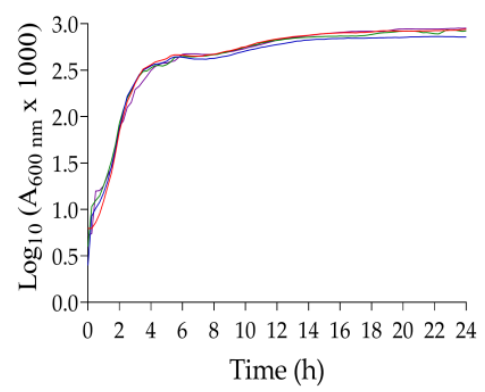

(b) M63

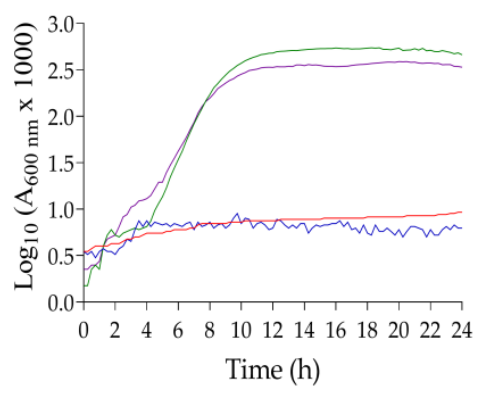

- ApurL::cat

- Tn 263

- ATCC

- $\Delta$ purL/purL+

(c) M63 + Inosine $50 \mu \mathrm{g} / \mathrm{mL}$

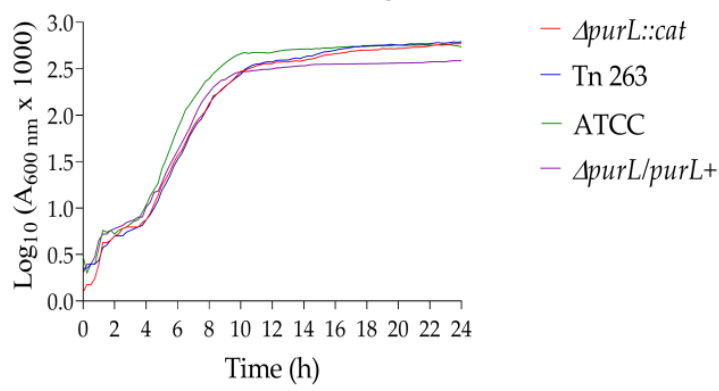

Figure 4. Fitness assay. (a) Growth curves in LB broth (b) Growth curves in M63 broth. (c) Growth curves in M63 broth supplemented with inosine $(50 \mu \mathrm{g} / \mathrm{mL})$. Growth rates were statistically evaluated via two-tailed Student $t$-test.

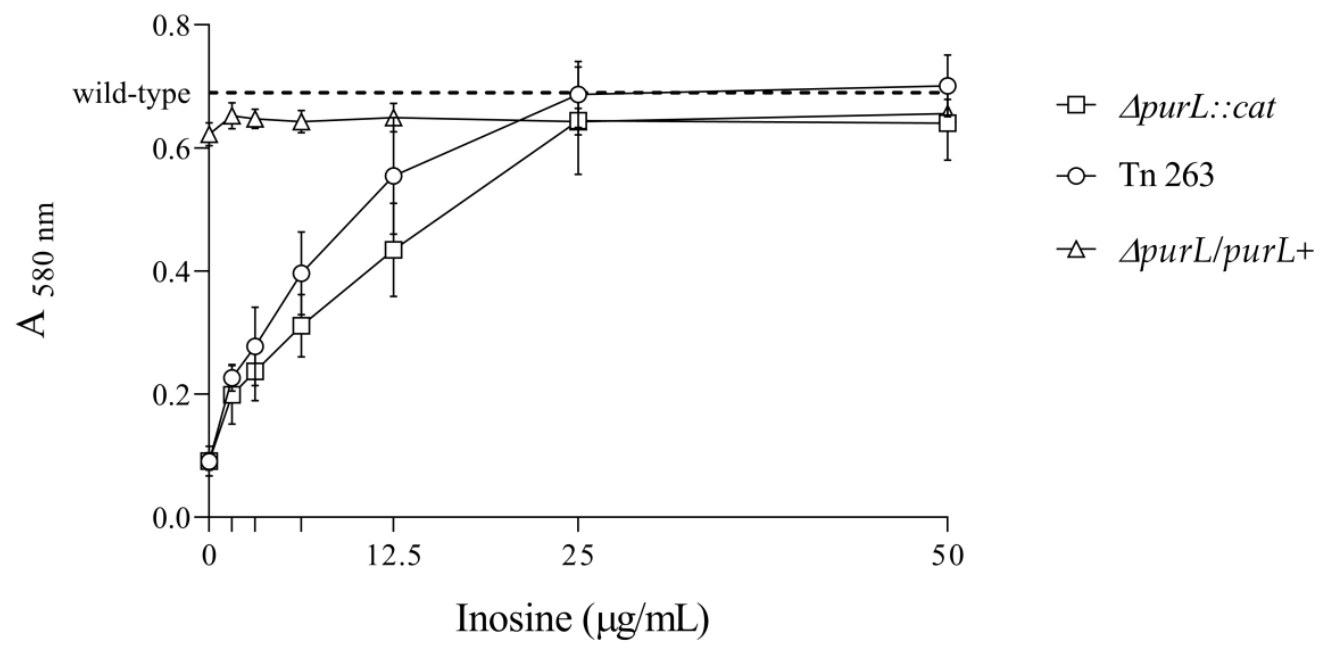

Figure 5. Biofilm formation of $\Delta$ purL::cat mutant, Tn263, and the complemented strain $\Delta p u r L / p u r L+$ using different concentrations of inosine. Each point in the curve represents mean values of $A_{580 \mathrm{~nm}}$ after $48 \mathrm{~h}$ of incubation; vertical bars correspond to standard deviations. The dashed line shows the absorbance value of the wild type strain, used as control. The results were analysed by One-way ANOVAs followed by post hoc Dunnett's multiple comparisons tests.

Curli production was also measured by CR assay. $\Delta p u r L:: c a t$ and Tn263 mutants showed an inability to bind CR and produced less curli fibers compared to the wt and the complemented strains. Curli production was restored in the mutants by supplementing agar medium with inosine $50 \mu \mathrm{g} / \mathrm{mL}$, demonstrating the interplay between curli production, purine biosynthesis pathway, and biofilm formation (Figure 6). 

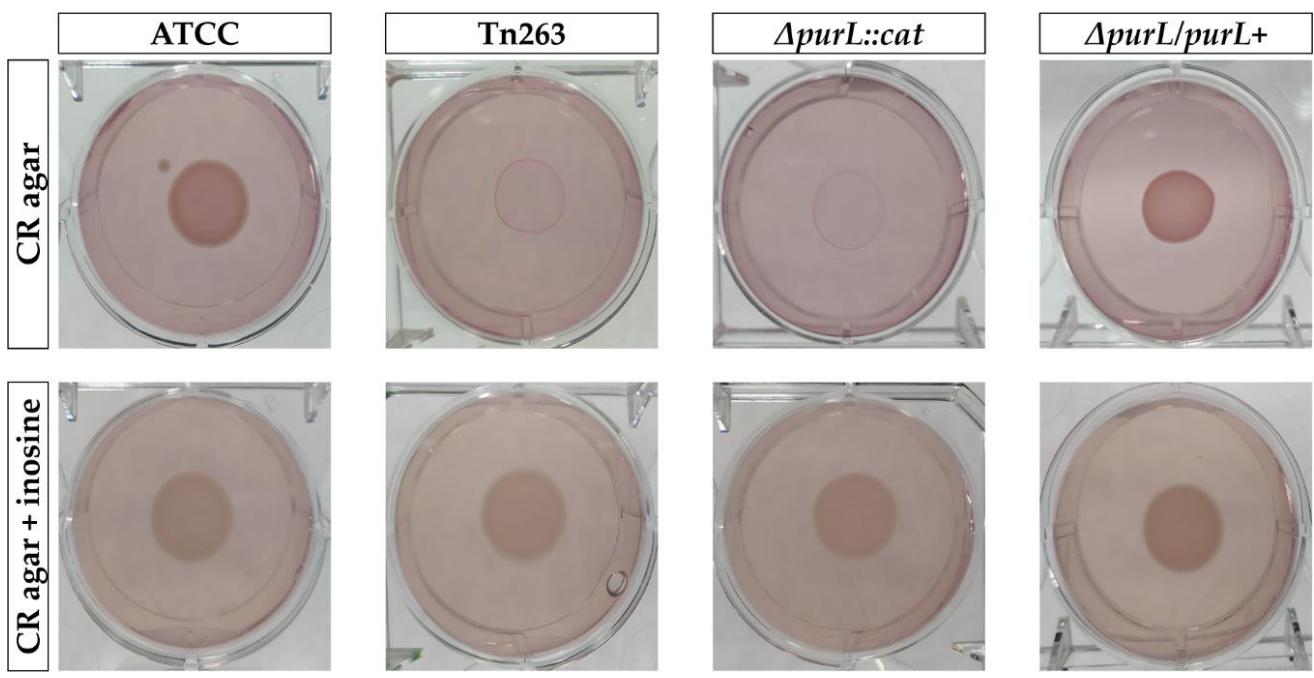

Figure 6. Curli production. Dark red colony in yeast and casamino acid agar (YESCA-CR AGAR) (ATCC and $\triangle$ purL/purL+) represents a curli producer, and light pink colonies (Tn263 and $\Delta p u r L:: c a t$ ) were associated with the defective phenotype. The defective phenotype of both mutants was restored in the YESCA-CR + Inosine agar.

\subsection{Proteomic Characterization of Mutant Tn 263}

\subsubsection{Comparative Proteomic Analyses of the wt and Tn263 by Two-Dimensional SDS-PAGE}

To investigate the effect of transposon insertion at a molecular level, the Tn263 mutant was compared to the wt strain using two-dimensional SDS-PAGE and mass spectrometry. Three biological replicates of each sample were studied (Figure 7, Supplementary Figure S2, and Supplementary Figure S3). Thirteen statistically significant spots were identified, 12 present in the wt strain, and one in the mutant strain. Among these, only spots with a score over 25 were considered for posterior analyses (ANOVA $p<0.05)$ (Supplementary Table S5). The molecular weight (Mw) and isoelectric point (pI) of proteins were determined using MASCOT software and are in line with their theoretical $\mathrm{Mw} / \mathrm{pI}$. The higher Mw might be the result of covalent binding, although lower Mw may be produced by proteolysis or post-translational changes. Figure 7 provides a representative image of 2D-gels in which spot differences are highlighted with arrows.

After mass-spectrometry identification and following pathway analysis, 13 proteins were classified into three categories: metabolism and cell maintenance; genetic information processing and signalling and cellular processes.

Within the metabolism regulation six proteins were included: CysJ, IlvC, ElbB, MgtA, Pta and AdhE. CysJ is a nicotinamide adenine dinucleotide phosphate (NADPH) flavin oxidoreductase that participates in the sulfite reductase complex (CysJ8I4). This protein is encoded by the cysJ gene, which plays an essential role in sulphur metabolism, required for de novo biosynthesis of L-cysteine. Aside from biosynthesis pathways, cysJ is also related to the detoxification system of toxic and mutagenic N-hydroxylated nucleobases [38]. In addition, IlvC, a Ketol-acid reducto-isomerase encoded by the $i l v C$ gene, is seen to participate during valine, leucine, and isoleucine biosynthesis. Glyoxalases are principally involved in the conversion of glyoxal to glycolate, therefore facilitating the conversion of toxins to a non-hazardous product [39]. E. coli possesses four glyoxalases which belong to the DJ-1 superfamily, i.e., HchA, YajL, YhbO, and ElbB, the latter present in our analysis. On the other hand, MgtA, a magnesium-transporting adenosine triphosphatase (ATPase), has a crucial function in transmembrane transport of electrons or protons. Phosphate acetyltransferase encoded by the $p t a$ gene is the first enzyme of the acetate pathway in the aerobic metabolism. The enzyme catalyzes the interconversion of acetyl-phosphate and acetyl coenzyme A. Finally, the only protein overexpressed in 
the Tn263 mutant was an aldehyde-alcohol dehydrogenase, encoded by the adhE gene $(p=0.0025)$. Under anaerobic conditions, AdhE catalyzes the reduction of acetyl-CoA to acetaldehyde, leading to an increase of $\mathrm{NAD}^{+}$.

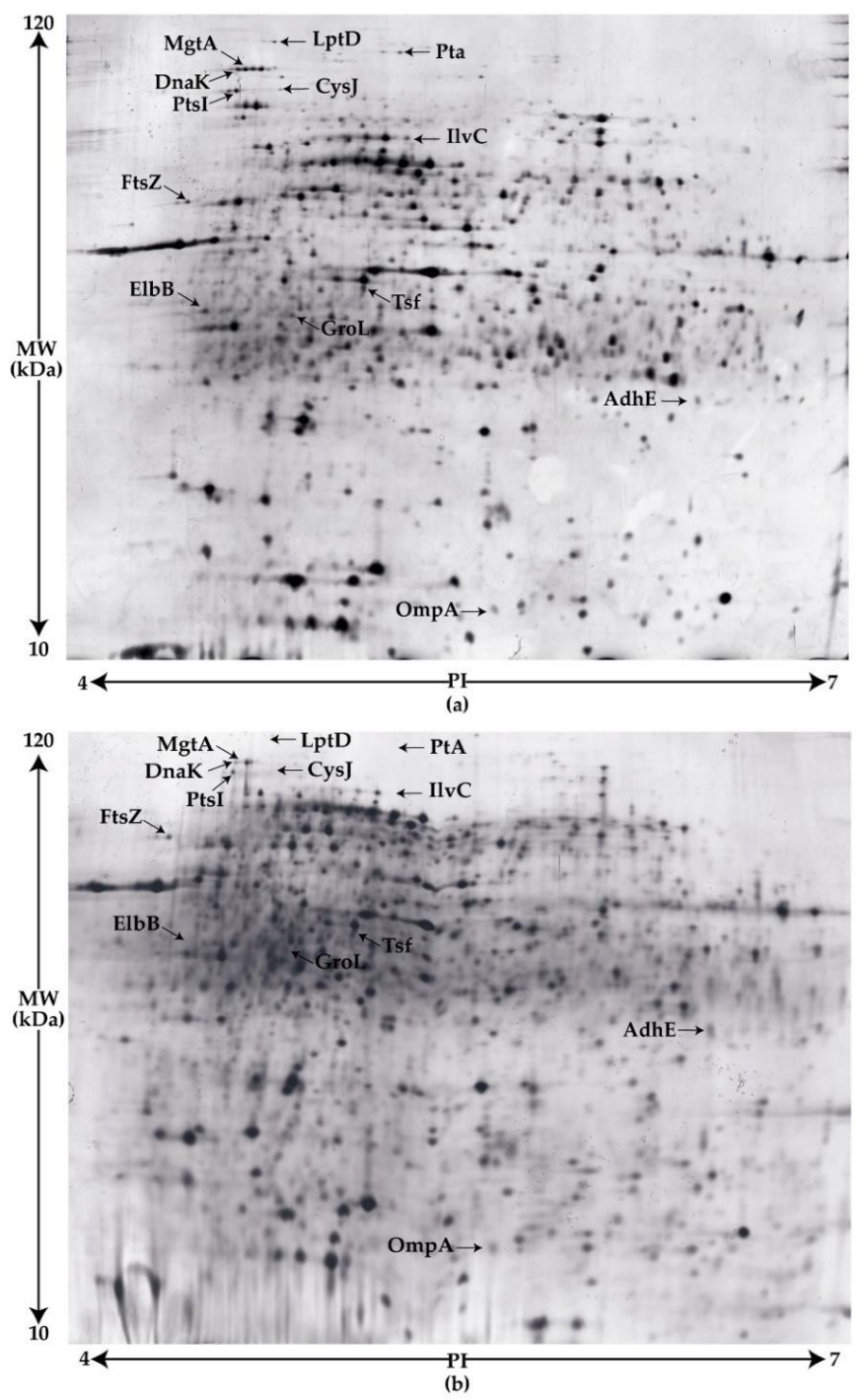

Figure 7. Two-dimensional sodium dodecyl sulfate polyacrylamide gel (SDS-PAGE) images. (a) wt strain; (b) Tn263. The arrows mark significant differences (ANOVA $p<0.05$ ) among the strains detected by Progenesis SameSpots 4.6.206. Further information about each spot identified can be found in the supporting information (Supplementary Table S5).

Regarding the proteins identified within the genetic information processing group, we identified the elongation factor thermostable (EF-ts) which is associated with the elongation factor Thermo-unstable (EF-Tu) and regulates the exchange of Guanosine 5'-Diphosphate (GDP) to GTP via aminoacyl-tRNA. The union of EF-ts to ternary structures (EF-Tu-GTP-aa-tRNA) could increase the maximum rate of translation [40]. The cell division protein FtsZ regulated by GTP hydrolysis was also detected. This protein marks the site where the Z-ring structure divides the cell. Z-ring mutation could alter the structure and lead to both the development of functional and non-functional cells [41]. Included in the list there was also the DnaK chaperone, the dominant bacterial heat shock protein (Hsp 70). This is involved in protein secretion and chromosomal DNA replication and interacts with $\sigma^{32}$ for controlling heat shock response. The last protein was the $60 \mathrm{kDa}$ chaperonin GroL. The GroL chaperonin, also stimulated by $\sigma^{32}$, mediates the assembly of unfolded polypeptides generated under 
stress conditions, and together with its regulator GroES, it is necessary for the proper folding of specific proteins.

Last, within the signalling and cellular process, we found the LptD (lipopolysaccharide transport) protein which, in combination with LptE protein, has an essential role in the production of lipopolysaccharide (LPS), the predominant component at the surface of the outer membrane (OM) of all Gram-negative bacteria. We also found the phosphoenolpyruvate-protein phosphotransferase enzyme 1 (PtsI) which participates in the phosphotransferase system related to phosphorylation of carbohydrates in E. coli. Finally, outer membrane protein A (OmpA) was identified as an abundant protein in E. coli, and it plays a significant role in maintaining cell integrity [42].

\subsubsection{Verification of Biofilm-Related Genes by q-RT-PCR}

The protein coding-genes corresponding to the proteins previously identified by SDS-PAGE and mass spectrometry were analysed to investigate possible translational alterations in the mutant sample. Further validation of these interesting targets was conducted by qRT-PCR between Tn263, the wt strain and the three biofilm-formers and three non-biofilm-formers clinical isolates.

mRNA detection by qRT-PCR and the subsequent analysis by $2^{-\Delta \Delta C t}$ method showed that three genes were downregulated ( $d n a K$, groL, and $a d h E)$ and six genes were overexpressed (lptD, cysJ, pta, $i l v C$, elbB and $p t s I$ ) in the Tn263 mutant compared to the wt strain. Four genes did not present changes among groups (tsf, ftsZ, ompA, and purL) (Figure 8a). To investigate whether these expression changes were related to the decreased biofilm formation capacity of the mutant, we assessed the expression levels of these genes in a collection of well-characterized E. coli clinical isolates. Two genes, adhE and ptsI presented a significant upregulation in the non-biofilm producers compared to the biofilm producer strains ( $p=0.0347$ and $p=0.0169$, respectively) (Figure $8 b$ ). In the first case, the Tn263 mutant showed upregulation of the AdhE protein, while it showed a low mRNA expression. However, mRNA expression in non-biofilm-formers remained upregulated. In the last case, the production of the PtsI protein was detected as being upregulated in the wt strain, whereas mRNA transcriptional levels were upregulated in both, the Tn263 and non-biofilm-formers.

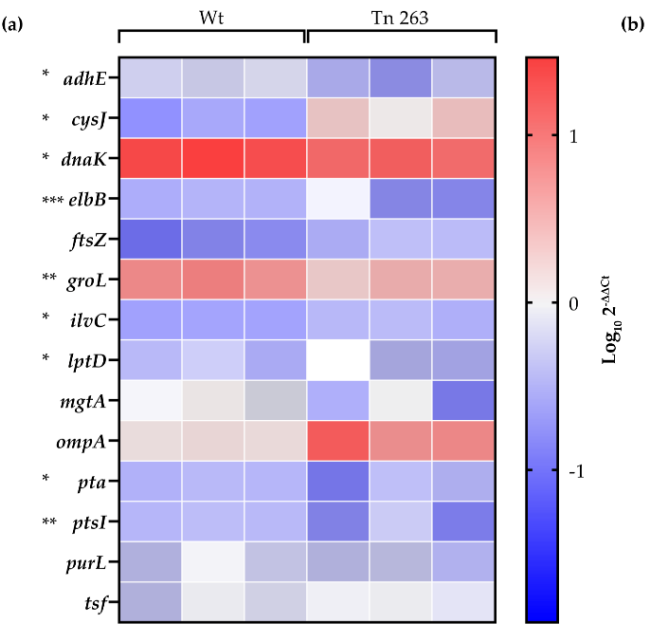

(b)

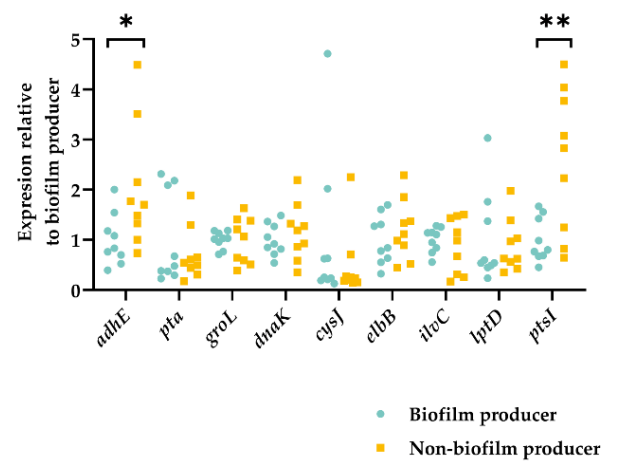

Figure 8. Analysis of the expression of selected genes in the wt and Tn263 mutants and in clinical isolates. (a) Heatmap showing the expression levels of biofilm-related genes in the wt and Tn263 mutant strains. Expression is presented as a logarithm of their $2^{-\Delta \Delta \mathrm{Ct}}$. Each square shows a biological replicate ( $n=3$ vs 3 ). (b) Scatter plot showing the expression of selected genes in biofilm producer and non-biofilm producer clinical isolates. Expression is normalised relative to the average expression of the biofilm producer isolates per each gene ( $n=X$ vs $X)$. Each clinical isolate was performed in triplicate. T test: ${ }^{*} p<0.05,{ }^{* *} p<0.01,{ }^{* * *} p<0.001$. 


\section{Discussion}

Bacteria have largely been investigated as planktonic cells. However, in many cases, bacteria grow in communities known as biofilms. These structures offer evolutionary advantages over their competitors and enable them to overcome environmental stresses. It is therefore important to understand the factors involved in the development of microbial biofilms that give them phenotypes different from their planktonic counterparts.

"Omics" techniques, such as high-throughput DNA sequencing, transcriptomic approaches, or proteomics, can clarify the underlying mechanisms of biofilm production. Progress in this field has indeed led to numerous studies that provide insight into molecular approaches [43].

The present study aimed to determine new genes involved in biofilm formation in E. coli using phenotypic and molecular tools comparing E. coli wt strain and the isogenic defective-biofilm mutants (Tn) generated by transposon insertion. Although the characterisation of the mutants with increased biofilm production was not within the scope of the present study, this could also lead to interesting results and warrants further investigations.

In the transposon mutant library, we found deficient mutants in biofilm formation. Two of these with the most significant loss of biofilm formation capacity were selected for the following analyses.

Tn463 was initially selected as a non-biofilm-forming mutant in the first phenotypic assays. However, it was later discarded because it had altered fitness and expression in curli fimbriae compared to the wt strain. Besides, the transposon was inserted into the $\operatorname{csg} A$ gene, a previously described gene that is involved in biofilm formation.

The second one, Tn263 mutant, differed from the wt in its proteomic and transcriptional profiles. DNA sequencing revealed a transposon insertion in the purL gene, which is involved in the de novo purine biosynthesis pathway. This pathway plays a critical role in the synthesis of DNA and RNA. In E. coli, the structural gene pur has various loci either individually (purT, purL, purC, purA) or collectively within operons (purF, purHD, purMN, purEK) [44]. Concretely, purL gene codes for formyl-glycinamide ribonucleotide amido-transferase (FGAR-AT), which is an enzyme that catalyses the fourth step of the purine biosynthetic pathway. This is an ATP-dependent conversion of formyl-glycinamide ribonucleotide (FGAR) and glutamine to yield N-formylglycinamidine ribonucleotide (FGAM), adenosine diphosphate (ADP), $\mathrm{Pi}$, and glutamate. In our mutant, the transposon was located in the N-terminal domain of the purL gene. Previous studies related three principal domains in purL: the glutaminase, the FGAM synthetase, and the N-terminal domains [45]. The glutaminase domain produces ammonia, which is transported to the FGAM synthetase domain. The N-terminal domain possesses an essential function for ammonia channel formation and posterior union between the two catalytic domains [46]. Changes in the N-terminal domain could potentially alter the interactions between other structures and block their function without transcriptional modification.

In order to determine whether the purL mutation could cause a fitness deficiency that would impede the biofilm formation, the mutant strain was grown in LB, without changing its growth rates, which suggests that the purL mutation does not affect its fitness in this growth medium. However, fitness was altered in M63 due to the alteration in the purine biosynthetic pathway. Biofilm formation was carried out in M63 medium at $30^{\circ} \mathrm{C}$ to favour the expression of genes involved in the biofilm formation $[20,21,47-50]$ as curli fimbriae, aggregated amyloid structures which promote cell aggregation and attachment to abiotic surfaces. They are promoted at a temperature less than $32{ }^{\circ} \mathrm{C}$ inducing transcription of the $\operatorname{csg} D E F G$ operon [51]. Nonetheless, Tn263 and $\triangle p u r L::$ cat mutants showed poor biofilm formation in the M63 medium compared to the wt strain. On the other hand, when we used the M63 broth supplemented with inosine in different concentrations, both mutants, Tn263 and SpurL::cat, regained the ability to form biofilm. Since both strains can form biofilm in the inosine-supplemented M63 medium, the lack of biofilm formation could be attributed to the purL disruption. The result was confirmed by the complementation of the knockout strain. Thus the lack of purines tends to reduce RNA synthesis by RNA polymerase or amino acid starvation resulting in a deficient biofilm phenotype. Nhu et al. found that the de novo purine biosynthesis is a critical pathway in curli production [36]. 
They hypothesise that a disruption in this pathway reduces the cyclic-di-GMP concentration inside the cell triggering the transcription of the master regulator $\operatorname{csg} D$. The authors found that $p u r F, p u r D, p u r M$ and purK mutants were unable to bind CR on YESCA-CR agar. In the same line, Garavaglia et al. also found that the mutation of the purine biosynthetic gene $\mathrm{purH}$ resulted in the inability to produce curli fibers [52].

Our results support these previous findings because the $\Delta p u r L:: c a t$ mutant exhibits a curli-deficient phenotype, resulting in decreased biofilm. However, after supplementation of the growth medium with inosine, both mutants, Tn263 and $\triangle p u r L:: c a t$, restored curli assembly suggesting that purL alteration and subsequent dysfunction in the purine pathway hinder the efficient transcription of the $\operatorname{csg} D E F G$ operon and $\operatorname{csg} D$ expression [52].

Biofilms are an important virulence factor involved in surface colonisation and subsequent infection, often causing chronic infections. A change in the purine synthesis pathway could reduce the colonisation rate and thus decrease biofilm infection. For example, disruption in the copA-purF or only the purF genes related to the de novo purine biosynthesis reduces uropathogenic E. coli (UPEC) internalization into bladder epithelial cells without alteration in epithelium colonisation [53]. Along the same lines, one study demonstrated that Burkholderia, defected in purl was unable to establish symbiotic accommodation in Riptortus sp. Burkholderia did not colonize Riptortus sp, even though the bacteria were capable of colonizing the host midgut. These results suggested that purine biosynthesis also could play an essential role in infection.

After finding that transposon was inserted into the purL gene, additional studies were conducted on the changes that this insertion caused at proteomic and transcriptional levels between wt and Tn263.

Comparative proteome analysis revealed 13 proteins statistically significant among wt and Tn263 (Figure 7). Among these proteins, five were found to be closely associated with biofilm regulation. The two chaperones, DnaK and GroL, are involved in stress response that usually results in the passage from individual cells to biofilm, inducing the loss of the flagella and performing maintenance activity in mature biofilm. Specifically, DnaK was involved in the transcriptional regulation of $f l h D C$, responsible for the flagellum biogenesis, an important organelle associated with biofilm formation, adhesion, and colonisation [54]. Moreover, a recent work by Sugimoto et al. [55] showed that the DnaK protein contributes to curli formation. Via rpoS, DnaK modulates the expression of the $c s g D E F$ operon which encodes for $\operatorname{CsgD}$ (master transcriptional regulator of curli) acting as a positive regulator of the $\operatorname{csg} B A C$ operon. This last operon encodes the $\mathrm{Csg} A$ and $\mathrm{CsgB}$ units, the major and minor structural components, respectively. On the other hand, studies in Cutibacterium acnes hypothesized that the GroL protein might contribute to the organisation of the biofilm matrix given its ability to bind to external DNA [56]. For this reason, the detection of proteins involved in maintaining a mature biofilm maintenance in the wt strain supports the idea that the Tn263 mutant was unable to form a biofilm.

Pta enzyme could be indirectly modulate the biofilm formation through acetate intermediates that can activate regulatory cascades of biofilm formation [57]. For example, acetylation produced by acetyl-coA from CpxA and UvrY, both members of the two-component regulatory system or RcsB, are involved in numerous regulatory DNA regions such as colanic acid synthesis, which enhances the 3D structure of the biofilm [58-60].

Another protein involved in biofilm formation that was detected in wt strains was PtsI. In this case, previous studies on Bacillus cereus showed that mutations in the ptsI gene cause a 70\% decrease in biofilm rates [61]. In avian pathogenic E. coli (APEC), ptsI deletion resulted in motility and biofilm-deficient bacteria, among other pathogenesis and phenotypic changes [62]. Furthermore, in E. coli, the internalisation of AI-2, a QS regulator, via Lsr activation, is mediated through ptsI phosphorylation [63]. Our results reinforce the hypothesis that PtsI is synthesized when bacteria develop the biofilm, given that PtsI is used to internalise AI-2 in the matrix. The fact that the mutant strain synthesises a lower amount of PtsI indicates that it is not in confluence and, therefore, it does not need to synthesize the protein. The last protein detected at high rates and associated with biofilm 
regulation in wt strain was OmpA. Indeed, the study by González Barrios et al. showed that the presence of an isogenic OmpA mutant decreases biofilm formation [64].

Finally, the only protein with high rates in Tn263 was AdhE. We hypothesise that the mutation in the purL gene leads to a hypoxic state, therefore activating anaerobic respiration. This idea is reinforced by studies carried out by Leonardo et al. who showed that using glucose as a carbon source in anaerobic conditions decreases NADH/NAD ${ }^{+}$ratio and changes the expression of the adhE gene [65]. Hence, the adhE gene would be regulated at the transcriptional level by the NADH/NAD ${ }^{+}$ratio.

Colón-González et al. also explained that anaerobic growth does not support biofilm formation in Escherichia coli K-12 by the enzymatic activity of the AdhE protein. adhE gene is induced during oxygen deficiency, and the authors found significant differences of growth in Congo red agar, where aerobically grown cells were red (curli + ) and anaerobically grown cells were white (curli -) [66]. This suggests a possible interaction between AdhE expression and defective curli fibers under anaerobic conditions. AdhE was found to be upregulated in Tn263 compared to the wt strain and does not produce curli fibers or biofilm. However, this gene is not upregulated among non-biofilm forming clinical strains. Therefore, we hypothesise that the expression of AdhE in this mutant could be strain-dependent because it has the purL gene affected by the effect of transposon insertion, whereas the purL gene is not affected in the wt or the clinical strains.

In summary, we have found a downregulation of Tn263 in the above mentioned proteins (with the exception of AdhE), all of which are related to the development and maintenance of the biofilm. Presumably, stress conditions caused by purine deficiency led to DNA damage in Tn263, which reduced its translational activity.

At the transcriptional level, the corresponding genes of these 13 proteins were analysed revealing interesting observations. The levels of expression of $l p t D, p t a, e l b B, p t s I, c y s J$ and $i l v C$ genes were higher in the Tn263 compared to the wt strain. Interestingly, elbB gene was overexpressed significantly in the Tn263 strain $(p<0.001)$. This overexpression can be caused by a high level of oxidative stress, which increases the production of glyoxals [67]. The last gene related to metabolic pathways, pta, showed increased transcriptional levels in the mutant strain, suggesting that it could use anaerobic metabolic pathways to synthesize ATP. Transcriptional changes related to the genetic information processing group showed lower levels of $d n a K(p<0.05)$ and groL $(p<0.01)$ in the Tn263 compared to the wt strain. These data are consistent with previous observations that show the induction of expression of some genes in the E. coli biofilm, such as dnaK [18]. The ptsI gene expression is reduced in the wt strain. As PtsI serves as a gateway for phosphoenolpyruvate (PEP), it is likely that the transcription of PtsI might be reduced once PEP is transported through PtsI. In contrast, the slower metabolism of the mutant strain may still contain PEP that could be transported by PtsI, whose mRNA remains active. The adhE gene had lower expression in the Tn263 mutant than in the wt strain. The transcription of this gene is induced under anaerobic conditions and regulated at the transcriptional and translational levels by NADH/NAD ${ }^{+}$and RNase III, respectively. For this reason, the mRNA transcripts remain at low rates in Tn263 by this regulation at transcriptional and translational levels $[65,68]$

Finally, to detect whether these transcriptional changes were related to a biofilm-deficient phenotype, the genes with statistical significance were tested on biofilm-forming and non-biofilmforming clinical strains. The results show disparity with those found in wt and Tn263. All genes reported equal expression in either group of clinical isolates. Among these nine genes, only two were significant (adhE and pta) and pta was the only one that followed the same pattern for both Tn263 and the non-biofilm-forming strains. This may be due to the insertion of the transposon in purL rather than being associated with a specific biofilm-forming or non-biofilm forming phenotype.

In conclusion, a mutation in the purL gene causes defective biofilm formation, which is related to the inability to form curli fibers, thus suggesting that this gene is essential for biofilm formation in E. coli. The proteomic study revealed pathways that belong to expressed biofilm factors, although the E. coli mutant was not able to form a biofilm. Given this reduction in biofilm formation and the influence of the biofilm on chronic infections, the identification of the purL gene as a target gene would 
contribute to understanding of the mechanisms of biofilm production and to develop new antibiofilm treatments against biofilm-related infections caused by this microorganism.

Supplementary Materials: The following are available online at http://www.mdpi.com/2076-0817/9/9/774/s1, Table S1: Biofilm classification of mutants. Low biofilm former (LF), high biofilm former (HF), biofilm former (F), Table S2: Primers used in the disruption and complementation of the purL gene, Table S3: Antibiotic resistance profiles of biofilm-forming and non-biofilm-forming clinical isolates, Table S4: qPCR primers used in this study, Table S5: Protein identification analysed by liquid chromatography coupled to mass spectrometry, Figure S1: Swimming assay. Figure S2: Two dimensional SDS-PAGE images of the wild type strain, Figure S3: Two dimensional SDS-PAGE images of the Tn263 mutant.

Author Contributions: Conceptualization, S.M.S., V.C., and Y.L.; methodology, V.C., V.B., M.R., Y.G., and Y.L.; statistical analysis, V.C. and V.B.; data curation, V.C. and V.B.; writing-original draft preparation, V.C., V.B., and S.M.S.; writing-review and editing, V.C., V.B., Y.L., and S.M.S. All authors have read and agreed to the published version of the manuscript.

Funding: This work was funded by the European Commission under the H2020 program, NoMorFilm Project (Grant Agreement 634588). ISGlobal is a CERCA center from the Generalitat of Catalunya and a Severo Ochoa Center (Spanish Ministry of Science, Innovations, and Universities) supported by Planes Nacionales de I+D+i 2008-2011/2013-2016 and Instituto de Salud Carlos III (PI19/00478), Subdirección General de Redes y Centros de Investigación Cooperativa, Ministerio de Economía y Competitividad, Spanish Network for Research in Infectious Diseases (REIPI RD12/0015/0013 and REIPI RD16/0016/0010) co-financed by European Development Regional Fund "A way to achieve Europe" and operative program Intelligent Growth 2014-2020. Victoria Ballén has a grant from COLCIENCIAS (Colombia).

Acknowledgments: We thank Yunuen Avalos for her helpful suggestions on protein and molecular biology protocols.

Conflicts of Interest: The authors declare no conflict of interest.

\section{References}

1. Blount, Z.D. The unexhausted potential of E. coli. Elife 2015, 4, 1-12. [CrossRef] [PubMed]

2. Bentley, R.; Meganathan, R. Biosynthesis of vitamin K (menaquinone) in bacteria. Microbiol. Rev. 1982, 46, 241-280. [CrossRef] [PubMed]

3. Lawrence, J.G.; Roth, J.R. Evolution of coenzyme B12 synthesis among enteric bacteria: Evidence for loss and reacquisition of a multigene complex. Genetics 1996, 142, 11-24. [PubMed]

4. $\quad$ Eggesbø, M.; Moen, B.; Peddada, S.; Baird, D.; Rugtveit, J.; Midtvedt, T.; Bushel, P.R.; Sekelja, M.; Rudi, K. Development of gut microbiota in infants not exposed to medical interventions. APMIS 2011, 119, 17-35. [CrossRef]

5. Pratt, L.A.; Kolter, R. Genetic analysis of Escherichia coli biofilm formation: Roles of flagella, motility, chemotaxis and type I pili. Mol. Microbiol. 1998, 30, 285-293. [CrossRef]

6. Soto, S.M. Importance of biofilms in urinary tract infections: New therapeutic approaches. Adv. Biol. 2014, 2014, 1-13. [CrossRef]

7. Millán-Rodríguez, F.; Palou, J.; Bujons-Tur, A.; Musquera-Felip, M.; Sevilla-Cecilia, C.; Serrallach-Orejas, M.; Baez-Angles, C.; Villavicencio-Mavrich, H. Acute bacterial prostatitis: Two different sub-categories according to a previous manipulation of the lower urinary tract. World J. Urol. 2006, 24, 45-50. [CrossRef]

8. Beloin, C.; Roux, A.; Ghigo, J.-M. Escherichia coli biofilms. Curr. Top. Microbiol. Immunol. 2008, 322, $249-289$. [CrossRef]

9. Wright, K.J.; Seed, P.C.; Hultgren, S.J. Uropathogenic Escherichia coli flagella aid in efficient urinary tract colonization. Infect. Immun. 2005, 73, 7657-7668. [CrossRef]

10. Donlan, R.M.; Costerton, J.W. Biofilms: Survival mechanisms of clinically relevant microorganisms. Clin. Microbiol. Rev. 2002, 15, 167-193. [CrossRef]

11. Gbejuade, H.O; Lovering, A.M.; Webb, J.C. The role of microbial biofilms in prosthetic joint infections. Acta Orthop. 2015, 86, 147-158. [CrossRef] [PubMed]

12. González, J.F.; Hahn, M.M.; Gunn, J.S. Chronic biofilm-based infections: Skewing of the immune response. Pathog. Dis. 2018, 76, 1-7. [CrossRef] [PubMed]

13. Høiby, N.; Bjarnsholt, T.; Givskov, M.; Molin, S.; Ciofu, O. Antibiotic resistance of bacterial biofilms. Int. J. Antimicrob. Agents 2010, 35, 322-332. [CrossRef] [PubMed]

14. Belas, R. Biofilms, flagella, and mechanosensing of surfaces by bacteria. Trends Microbiol. 2014, 22, 517-527. [CrossRef] 
15. Kaplan, J.B. Biofilm dispersal: Mechanisms, clinical implications, and potential therapeutic uses. J. Dent. Res. 2010, 89, 205-218. [CrossRef] [PubMed]

16. Sharma, G.; Sharma, S.; Sharma, P.; Chandola, D.; Dang, S.; Gupta, S.; Gabrani, R. Escherichia coli biofilm: Development and therapeutic strategies. J. Appl. Microbiol. 2016, 121, 309-319. [CrossRef] [PubMed]

17. Klemm, P.; Schembri, M. Type 1 fimbriae, curli, and antigen 43: Adhesion, colonization, and biofilm formation. Ecosal Plus 2013, 1, 1-18. [CrossRef] [PubMed]

18. Beloin, C.; Valle, J.; Latour-Lambert, P.; Faure, P.; Kzreminski, M.; Balestrino, D.; Haagensen, J.A.J.; Molin, S.; Prensier, G.; Arbeille, B.; et al. Global impact of mature biofilm lifestyle on Escherichia coli K-12 gene expression. Mol. Microbiol. 2004, 51, 659-674. [CrossRef]

19. Mehrotra, A. Bacterial Biofilms. Pediatric Asthmaall. Immunol. 2007, 20, 191-195. [CrossRef]

20. Prigent-Combaret, C.; Prensier, G.; Le Thi, T.T.; Vidal, O.; Lejeune, P.; Dorel, C. Developmental pathway for biofilm formation in curli-producing Escherichia coli strains: Role of flagella, curli and colanic acid. Environ. Microbiol. 2000, 2, 450-464. [CrossRef]

21. Cepas, V.; López, Y.; Gabasa, Y.; Martins, C.B.; Ferreira, J.D.; Correia, M.J.; Santos, L.M.A.; Oliveira, F.; Ramos, V.; Reis, M.; et al. Inhibition of bacterial and fungal biofilm formation by 675 extracts from microalgae and cyanobacteria. Antibiotics 2019, 8, 77. [CrossRef] [PubMed]

22. Hultgren, S.J.; Schwan, W.R.; Schaeffer, A.J.; Duncan, J.L. Regulation of production of type 1 pili among urinary tract isolates of Escherichia coli. Infect. Immun. 1986, 54, 613-620. [CrossRef] [PubMed]

23. Martin, M. Cutadapt removes adapter sequences from high-throughput sequencing reads. Embnet J. 2011, 17, 10. [CrossRef]

24. Schmieder, R.; Edwards, R. Quality control and preprocessing of metagenomic datasets. Bioinformatics 2011, 27, 863-864. [CrossRef]

25. Bankevich, A.; Nurk, S.; Antipov, D.; Gurevich, A.A.; Dvorkin, M.; Kulikov, A.S.; Lesin, V.M.; Nikolenko, S.I.; Pham, S.; Prjibelski, A.D.; et al. SPAdes: A new genome assembly algorithm and its applications to single-cell sequencing. J. Comput. Biol. 2012, 19, 455-477. [CrossRef]

26. Li, H.; Durbin, R. Fast and accurate short read alignment with Burrows-Wheeler transform. Bioinformatics 2009, 25, 1754-1760. [CrossRef]

27. Darling, A.C.E. Mauve: Multiple alignment of conserved genomic sequence with rearrangements. Genome Res. 2004, 14, 1394-1403. [CrossRef] [PubMed]

28. Datsenko, K.A.; Wanner, B.L. One-step inactivation of chromosomal genes in Escherichia coli K-12 using PCR products. Proc. Natl. Acad. Sci. USA 2000, 97, 6640-6645. [CrossRef]

29. Görg, A.; Weiss, W.; Dunn, M.J. Current two-dimensional electrophoresis technology for proteomics. Proteomics 2004, 4, 3665-3685. [CrossRef]

30. Laemmli, U.K. Cleavage of structural proteins during the assembly of the head of bacteriophage T4. Nature 1970, 227, 680-685. [CrossRef]

31. Chevallet, M.; Luche, S.; Rabilloud, T. Silver staining of proteins in polyacrylamide gels. Nat. Protoc. 2006, 1, 1852-1858. [CrossRef]

32. Marcelino, I.; Colomé-Calls, N.; Holzmuller, P.; Lisacek, F.; Reynaud, Y.; Canals, F.; Vachiéry, N. Sweet and sour ehrlichia: Glycoproteomics and phosphoproteomics reveal new players in Ehrlichia ruminantium physiology and pathogenesis. Front. Microbiol. 2019, 10, 1-18. [CrossRef]

33. CLSI. Performance Standards for Antimicrobial Susceptibility, 29th ed.; CLSI supplement M100; Clinical and Laboratory Standards Institute: Wayne, PA, USA, 2019.

34. Jandu, N.; Ho, N.K.L.; Donato, K.A.; Karmali, M.A.; Mascarenhas, M.; Duffy, S.P.; Tailor, C.; Sherman, P.M. Enterohemorrhagic Escherichia coli O157:H7 gene expression profiling in response to growth in the presence of host epithelia. PLoS ONE 2009, 4, e4889. [CrossRef]

35. Reid, S.D.; Herbelin, C.J.; Bumbaugh, A.C.; Selander, R.K.; Whittam, T.S. Parallel evolution of virulence in pathogenic Escherichia coli. Nature 2000, 406, 64-67. [CrossRef]

36. Nhu, N.T.K.; Phan, M.D.; Peters, K.M.; Lo, A.W.; Forde, B.M.; Chong, T.M.; Yin, W.F.; Chan, K.G.; Chromek, M.; Brauner, A.; et al. Discovery of new genes involved in curli production by a uropathogenic Escherichia coli strain from the highly virulent O45:K1:H7 lineage. MBio 2018, 9, 1-16. [CrossRef]

37. Serra, D.O.; Richter, A.M.; Hengge, R. Cellulose as an architectural element in spatially structured Escherichia coli biofilms. J. Bacteriol. 2013, 195, 5540-5554. [CrossRef] 
38. Kozmin, S.G.; Wang, J.; Schaaper, R.M. Role for CysJ flavin reductase in molybdenum cofactor-dependent resistance of Escherichia coli to 6-N-Hydroxylaminopurine. J. Bacteriol. 2010, 192, 2026-2033. [CrossRef]

39. Lee, C.; Lee, J.; Lee, J.; Park, C. Characterization of the Escherichia coli YajL, YhbO and ElbB glyoxalases. FEMS Microbiol. Lett. 2016, 363, fnv239. [CrossRef]

40. Burnett, B.J.; Altman, R.B.; Ferrao, R.; Alejo, J.L.; Kaur, N.; Kanji, J.; Blanchard, S.C. Elongation factor Ts directly facilitates the formation and disassembly of the Escherichia coli elongation factor Tu.GTP.Aminoacyl-tRNA ternary complex. J. Biol. Chem. 2013, 288, 13917-13928. [CrossRef]

41. Stricker, J.; Erickson, H.P. In Vivo characterization of Escherichia coli ftsZ mutants: Effects on Z-Ring structure and function. J. Bacteriol. 2003, 185, 4796-4805. [CrossRef] [PubMed]

42. Sonntag, I.; Schwarz, H.; Hirota, Y.; Henning, U. Cell envelope and shape of Escherichia coli: Multiple mutants missing the outer membrane lipoprotein and other major outer membrane proteins. J. Bacteriol. 1978, 136, 280-285. [CrossRef]

43. Franklin, M.J.; Chang, C.; Akiyama, T.; Bothner, B. New technologies for studying biofilms. Microbiol. Spectr. 2015, 3, 1-24. [CrossRef]

44. Green, S.M.; Malik, T.; Giles, I.G.; Drabble, W.T. The purB gene of Escherichia coli K-12 is located in an operon. Microbiology 1996, 142, 3219-3230. [CrossRef]

45. Anand, R.; Hoskins, A.A.; Stubbe, J.; Ealick, S.E. Domain organization of Salmonella typhimurium formylglycinamide ribonucleotide amidotransferase revealed by X-ray crystallography. Biochemistry 2004, 43, 10328-10342. [CrossRef]

46. Zhang, Y.; Morar, M.; Ealick, S.E. Structural biology of the purine biosynthetic pathway. Cell. Mol. Life Sci. 2008, 65, 3699-3724. [CrossRef]

47. Soto, S.M.; Smithson, A.; Martinez, J.A.; Horcajada, J.P.; Mensa, J.; Vila, J. Biofilm formation in uropathogenic Escherichia coli strains: Relationship with prostatitis, urovirulence factors and antimicrobial resistance. J. Urol. 2007, 177, 365-368. [CrossRef]

48. O'Toole, G.A.; Kolter, R. Flagellar and twitching motility are necessary for Pseudomonas aeruginosa biofilm development. Mol. Microbiol. 1998, 30, 295-304. [CrossRef]

49. Vidal, O.; Longin, R.; Prigent-Combaret, C.; Dorel, C.; Hooreman, M.; Lejeune, P. Isolation of an Escherichia coli K-12 mutant strain able to form biofilms on inert surfaces: Involvement of a new ompR allele that increases curli expression. J. Bacteriol. 1998, 180, 2442-2449. [CrossRef]

50. Cepas, V.; López, Y.; Muñoz, E.; Rolo, D.; Ardanuy, C.; Martí, S.; Xercavins, M.; Horcajada, J.P.; Bosch, J.; Soto, S.M. Relationship between biofilm formation and antimicrobial resistance in gram-negative bacteria. Microb. Drug Resist. 2019, 25, 72-79. [CrossRef]

51. Gualdi, L.; Tagliabue, L.; Bertagnoli, S.; Ieranò, T.; De Castro, C.; Landini, P. Cellulose modulates biofilm formation by counteracting curli-mediated colonization of solid surfaces in Escherichia coli. Microbiology 2008, 154, 2017-2024. [CrossRef]

52. Garavaglia, M.; Rossi, E.; Landini, P. The pyrimidine nucleotide biosynthetic pathway modulates production of biofilm determinants in Escherichia coli. PLOS ONE 2012, 7, e31252. [CrossRef]

53. Shaffer, C.L.; Zhang, E.W.; Dudley, A.G.; Dixon, B.R.E.A.; Guckes, K.R.; Breland, E.J.; Floyd, K.A.; Casella, D.P.; Algood, H.M.S.; Clayton, D.B.; et al. Purine biosynthesis metabolically constrains intracellular survival of uropathogenic Escherichia Coli. Infect. Immun. 2017, 85, 1-14. [CrossRef]

54. Prüß, B.M.; Besemann, C.; Denton, A.; Wolfe, A.J. A complex transcription network controls the early stages of biofilm development by Escherichia Coli. J. Bacteriol. 2006, 188, 3731-3739. [CrossRef]

55. Sugimoto, S.; Arita-Morioka, K.; Terao, A.; Yamanaka, K.; Ogura, T.; Mizunoe, Y. Multitasking of Hsp70 chaperone in the biogenesis of bacterial functional amyloids. Commun. Biol. 2018, 1, 52. [CrossRef]

56. Gannesen, A.V.; Zdorovenko, E.L.; Botchkova, E.A.; Hardouin, J.; Massier, S.; Kopitsyn, D.S.; Gorbachevskii, M.V.; Kadykova, A.A.; Shashkov, A.S.; Zhurina, M.V.; et al. Composition of the biofilm matrix of Cutibacterium acnes acneic strain RT5. Front. Microbiol. 2019, 10. [CrossRef] [PubMed]

57. Prüß, B.M.; Verma, K.; Samanta, P.; Sule, P.; Kumar, S.; Wu, J.; Christianson, D.; Horne, S.M.; Stafslien, S.J.; Wolfe, A.J.; et al. Environmental and genetic factors that contribute to Escherichia coli K-12 biofilm formation. Arch. Microbiol. 2010, 192, 715-728. [CrossRef] [PubMed]

58. Gervais, F.G.; Phoenix, P.; Drapeau, G.R. The rcsB gene, a positive regulator of colanic acid biosynthesis in Escherichia coli, is also an activator of ftsZ expression. J. Bacteriol. 1992, 174, 3964-3971. [CrossRef] 
59. Limoli, D.H.; Jones, C.J.; Wozniak, D.J. Bacterial extracellular polysaccharides in biofilm formation and function. Microbiol. Spectr. 2015, 3, 1191-1200. [CrossRef] [PubMed]

60. Ma, Q.; Wood, T.K. Protein acetylation in prokaryotes increases stress resistance. Biochem. Biophys. Res. Commun. 2011, 410, 846-851. [CrossRef]

61. Xu, Y.-B.; Chen, M.; Zhang, Y.; Wang, M.; Wang, Y.; Huang, Q.; Wang, X.; Wang, G. The phosphotransferase system gene ptsI in the endophytic bacterium Bacillus cereus is required for biofilm formation, colonization, and biocontrol against wheat sharp eyespot. FEMS Microbiol. Lett. 2014, 354, 142-152. [CrossRef]

62. Wu, X.; Lv, X.; Lu, J.; Yu, S.; Jin, Y.; Hu, J.; Zuo, J.; Mi, R.; Huang, Y.; Qi, K.; et al. The role of the ptsI gene on AI-2 internalization and pathogenesis of avian pathogenic Escherichia coli. Microb. Pathog. 2017, 113, 321-329. [CrossRef] [PubMed]

63. Pereira, C.S.; Santos, A.J.M.; Bejerano-Sagie, M.; Correia, P.B.; Marques, J.C.; Xavier, K.B. Phosphoenolpyruvate phosphotransferase system regulates detection and processing of the quorum sensing signal autoinducer- 2 . Mol. Microbiol. 2012, 84, 93-104. [CrossRef] [PubMed]

64. Barrios, A.F.G.; Zuo, R.; Ren, D.; Wood, T.K. Hha, YbaJ, and OmpA regulate Escherichia coli K12 biofilm formation and conjugation plasmids abolish motility. Biotechnol. Bioeng. 2006, 93, 188-200. [CrossRef] [PubMed]

65. Leonardo, M.R.; Dailly, Y.; Clark, D.P. Role of NAD in regulating the adhE gene of Escherichia coli. J. Bacteriol. 1996, 178, 6013-6018. [CrossRef]

66. Colón-González, M.; Méndez-Ortiz, M.M.; Membrillo-Hernández, J. Anaerobic growth does not support biofilm formation in Escherichia coli K-12. Res. Microbiol. 2004, 155, 514-521. [CrossRef] [PubMed]

67. Thornalley, P.J.; Langborg, A.; Minhas, H.S. Formation of glyoxal, methylglyoxal and 3-deoxyglucosone in the glycation of proteins by glucose. Biochem. J. 1999, 344, 109. [CrossRef] [PubMed]

68. Aristarkhov, A.; Mikulskis, A.; Belasco, J.G.; Lin, E.C.C. Translation of the adhE transcript to produce ethanol dehydrogenase requires RNase III cleavage in Escherichia coli. J. Bacteriol. 1996, 178, 4327-4332. [CrossRef]

(C) 2020 by the authors. Licensee MDPI, Basel, Switzerland. This article is an open access article distributed under the terms and conditions of the Creative Commons Attribution (CC BY) license (http://creativecommons.org/licenses/by/4.0/). 